\title{
Optical Band Gap, Oxidation Polarizability, Optical Basicity and Electronegativity Measurements of Silicate Glasses Using Ellipsometer and Abbe Refractometer
}

\author{
Zahid Hussain \\ Department of Electrical and Electronic Engineering, Imperial College of Science, Technology and Medicine, London, UK \\ Email: hzzhussain@aol.com
}

How to cite this paper: Hussain, Z. (2021) Optical Band Gap, Oxidation Polarizability, Optical Basicity and Electronegativity Measurements of Silicate Glasses Using Ellipsometer and Abbe Refractometer. New Journal of Glass and Ceramics, 11, 1-33. https://doi.org/10.4236/njgc.2021.111001

Received: September 22, 2020

Accepted: January 5, 2021

Published: January 8, 2021

Copyright (อ 2021 by author(s) and Scientific Research Publishing Inc. This work is licensed under the Creative Commons Attribution International License (CC BY 4.0).

http://creativecommons.org/licenses/by/4.0/ (c) (i) Open Access

\begin{abstract}
The values of refractive index $(n)$ for silicate glasses (silica, soda lime and borosilicate 7059) are decreased from 1.5119 to $1.5111,1.5086$ to 1.5065 and 1.5296 to 1.5281 , respectively; and the optical band gap $\left(E_{g}\right)$ is increased from 9.8 to $9.81 \mathrm{eV}, 9.845$ to $9.88 \mathrm{eV}$ and 9.56 to $9.58 \mathrm{eV}$, respectively over the temperature range 295 - $473 \mathrm{~K}$ using ellipsometer at wavelength $632.8 \mathrm{~nm}$. While $n$ is decreased from 1.5276 to $1.5274,1.5074$ to 1.5070 and from 1.5283 to 1.5281 , respectively; and $E_{g}$ is increased from 9.59 to $9.592 \mathrm{eV}, 9.862$ to $9.870 \mathrm{eV}$, and 9.574 to $9.58 \mathrm{eV}$, respectively over the temperature range 297 $322 \mathrm{~K}$ using Abbe refractometer at wavelength $589.3 \mathrm{~nm}$. The values of oxide ion polarizability $\left[\alpha_{02-}(n)\right.$ and $\left.\alpha_{02-}\left(E_{g}\right)\right]$ regarding silica, soda lime and borosilicate 7059 glasses are decreased from 1.3427 to $1.3408,1.6014$ to 1.5941 , 1.4329 to 1.4193 , respectively over the temperature range 295 - $473 \mathrm{~K}$ using ellipsometer; and are decreased from 1.3786 to $1.3764,1.5991$ to 1.5969 , 1.4297 to 1.4191 , respectively over the temperature range 297 - $322 \mathrm{~K}$ using Abbe refractometer. Similarly, the values of optical basicity [ $A(n)$ and $A\left(E_{g}\right)$ ] of silica, soda lime, and borosilicate 7059 glasses are decreased from 0.4272 to $0.4245,0.6271$ to $0.6224,0.5045$ to 0.4933 , respectively over the temperature range 295 - $473 \mathrm{~K}$ using ellipsometer; and are decreased from 0.4586 to $0.4567,0.6256$ to $0.6242,0.5018$ to 0.4930 , respectively over the temperature range 297 - $322 \mathrm{~K}$ using Abbe refractometer. Further, we have found that for silica, soda lime and borosilicate 7059 , the values of electronegativity $\left.\left(\xi_{\text {lav }}\right) \zeta_{1 a v}\right)$ using Zahid numerical model [based on $\boldsymbol{\alpha}_{\mathrm{O2}-}(\boldsymbol{n})$ and $\boldsymbol{A}(\boldsymbol{n})$ ] are increased from 5.1035 to $5.5504,4.0393$ to $4.830,4.8143$ to 5.0111 , respectively over the temperature range $295-473 \mathrm{~K}$ using ellipsometer; while these values are increased from 5.0657 to $5.2149,5.0657$ to $5.2149,4.8357$ to 5.0111 ,
\end{abstract}


respectively over the temperature range 297 - $322 \mathrm{~K}$ using Abbe refractometer. It is very clear from this research report that both refractive index and optical band gap-based-oxide ion polarizability and optical basicity have the same decreasing trend as the temperature is increased, and this trend indicates that the reported glasses have a very small amount of electronic polarizability. Moreover, this decreasing trend occurs due to the decreasing amount of non-bridging oxygen (NBO) which in turn caused a decrease in refractive index within the silicate glass system at higher temperature. Since the calculated values of electronegativity are found to be in the range 4.0393 5.5504 for the reported silicate glasses, so all these glasses have an ionic character. Moreover, low values of optical basicity and of oxide ion polarizability suggest that the silicate glasses are not novel glasses (optical functional glasses) for non-linear optical (NLO) devices or for three dimensional displays.

\section{Keywords}

Glass, Optical Properties, Thermal Properties, Physical Properties, Ellipsometry

\section{Introduction}

Among different classes of materials, glasses have acknowledged advantages because of their diverse technological and biological applications including solid state lasers, optical filters, water treatment and as biomaterials [1] [2] [3] [4]. Among the optical glasses, silicate glasses are of low cost and have high optical transmission in the visible and near-infrared spectral range which makes them commonly used as microscope slides [5] [6]. Inorganic glasses, glass-ceramic and glaze materials have widely been used in fields such as electrical engineering/electronics/sensors and solar energy [7]-[15]. Silicate glasses have also great use in optics/optical telecommunications [16] [17], structural mechanics [7] [18], medical [19] [20], nuclear technology [21] [22], superconductors [21] [23] and in microfluidics [24] [25]. Recently many researchers study glasses as switching and memory devices and as superior insulators and dielectrics [26] [27]. Silicate glass (silica, soda lime, borosilicate 7059) is an attractive host matrix for transition metal ions because of its excellent optical and mechanical properties, good chemical stability, low non-linear refractive index, large tensile fracture strength and due to good durability [4] [28] [29]. Oxide glasses take a considerable attention in view of their potential use in the areas of opto-electronics such as laser technology, optical fibers, non-linear optical devices and sensor systems [30] [31].

The soda lime silicate glass has been found to be a suitable optical material with high transparency, low melting point, high thermal stability and good rare-earth ions solubility [32] [33]. Silica glass, because of its favourable physical, 
chemical, and optical characteristics, has been used in numerous applications such as laboratory glassware, as lenses or beam splitters, for lighting and IR heating, in telecommunications, in fiber optics and in mico and optoelectronics [34] [35]. Further, silicon oxide $\left(\mathrm{SiO}_{2}\right)$ has been used as substrates for electronic displays, optical fibers, optical disc, medical and dental implants and for radiation shielding [36] [37] [38]. Containers, windows, lighting, insulation, fibre, and other hand crafted art objects are typical of traditional uses of silicate glasses [39] [40].

In nuclear industry, borosilicate glass is mainly used as matrix for immobilizing the radioactive ions present in the waste generated from the nuclear reactors [41] [42] [43]. Due to these interesting physical properties, borosilicate glasses can be used as laser host matrices after doping with rare earth oxides [44] [45].

The optical research on rare earth (RE) doped glasses draw great consideration due to their broad application in optical areas like optical switches for laser and sensors and optical communications [46] [47]. These types of glasses can be implemented in high density optical memory applications such as coast-guard communication, colour display and for solar cells etc. [48] [49]. Glasses emerge as an important class of materials that exhibit very attractive properties and have shown great potential in variety of applications such as optical switches, solid oxide fuel cells, microelectronics, telecommunications and for medical [50] [51] [52].

In this paper, our main aim is to report temperature dependent linear optical and physical properties of silicate glasses (silica, soda lime, borosilicate 7059). In the first step, we have measured the temperature dependent refractive index ( $n$ ) data on silicate glasses using single wavelength manual ellipsometry and Abbe refractometer over a temperature range 295 - $473 \mathrm{~K}$. It should be noted that the absorption index $(k)$ of silicate glasses is very small in the visible and near infrared spectral range and may be assumed to be zero for all practical purposes. In the second step, we have generated the data on molar refraction $\left(R_{m}\right)$, molar electronic polarizability $\left(\alpha_{m e}\right)$, optical band gap $\left(E_{g}\right)$, Oxide ion polarizability $\left(\alpha_{02}\right)$ and optical basicity $(A)$ regarding silicate microscope glass slides. In the third step, we have generated temperature dependent electronegativity data on silicate glasses with the application of new models (Zahid models) along with the old models using the obtained values of oxide ion polarizability $\left(\alpha_{02}-\right)$ and optical basicity $[A(n)]$, and this new data is found to be in a good agreement with the literature. The reported data has also been interpreted using different empirical models for technical applications.

\section{Experimental Techniques}

\subsection{Sample Preparation}

Silicate glasses mean silica, soda lime silica glass, and borosilicate glass. Silica is the dioxide form of silica, $\mathrm{SiO}_{2}$, and occurs mostly as quartz sand, flint, and agate. It is formed when silicon is exposed to oxygen. The commercially supplied 
$\mathrm{SiO}_{2}$ glasses (microscope slides) employed in this study have mass density as 2.65 $\mathrm{g} / \mathrm{cm}^{3}$ and molecular weight as $60.08 \mathrm{~g} / \mathrm{mol}$. The other silicate glasses (soda lime and borosilicate microscope slides) are also commercially supplied. A typical composition of soda lime silicate glass is $73 \% \mathrm{SiO}_{2}+15 \% \mathrm{Na}_{2} \mathrm{O}+7 \% \mathrm{CaO}+4 \%$ $\mathrm{MgO}+1 \% \mathrm{Al}_{2} \mathrm{O}_{3}$, and its mass density is $2.5 \mathrm{~g} / \mathrm{cm}^{3}$. Since the molecular weights of all these compositions are known in the literature and so they can be printed as $60.08 \mathrm{~g} / \mathrm{mol}, 61.98 \mathrm{~g} / \mathrm{mol}, 56.0774 \mathrm{~g} / \mathrm{mol}, 40.3044 \mathrm{~g} / \mathrm{mol}$, and $101.96 \mathrm{~g} / \mathrm{mol}$, respectively. We have measured the molecular weight of soda lime as the average of sums of the \% molecular weights of all constituents and measuring the molecular weight of soda lime using the mole \% of all participating cations in the composition. As a result, the average molecular weight of soda lime silicate is measured as $59.34 \mathrm{~g} / \mathrm{mol}$.

The typical chemical composition of borosilicate 7059 glass is $80 \% \mathrm{SiO}_{2}+13 \%$ $\mathrm{B}_{2} \mathrm{O}_{3}+4 \% \mathrm{Na}_{2} \mathrm{O}+3 \% \mathrm{Al}_{2} \mathrm{O}_{3}$, and its mass density is $2.76 \mathrm{~g} / \mathrm{cm}^{3}$. The molecular weights of all compositions relating to 7059 glass (as found in the literature) can be printed respectively as $60.08 \mathrm{~g} / \mathrm{mol}, 69.62 \mathrm{~g} / \mathrm{mol}, 61.98 \mathrm{~g} / \mathrm{mol}$ and 101.96 . Following the method as we did for soda lime glass, the average molecular weight of 7059 silicate glass is determined as $62.69 \mathrm{~g} / \mathrm{mol}$.

Next, molecular volume $\left(V_{m}\right)$ of any solid $=$ Molecular weight $/$ Mass density $=$ $M / \rho=\mathrm{cc} / \mathrm{mol}$. So, for silica glass, $V_{m}=60.08 / 2.65=22.672 \mathrm{cc} / \mathrm{mol}$; for soda lime, $V_{m}=60.08 / 2.65=23.74 \mathrm{cc} / \mathrm{mol}$; and for 7059 silicate glass, $V_{m}=$ $60.08 / 2.65=22.714 \mathrm{cc} / \mathrm{mol}$.

These silicate glasses are available in many forms and sizes such as rod, tube, or microscopic slide. In this work, silicate flat glasses were obtained commercially as microscopic slides. Microscope slides of these glasses measure about 75 $\mathrm{mm}$ by $25 \mathrm{~mm}$ and are about $1 \mathrm{~mm}$ thick.

\subsection{Substrate Cleaning Procedure}

Silica and other glass slides were washed with "Micro" cleaning fluids (purchased from International Products Corporation) and rinsed in tap water and distilled water. Having been left to soak in freshly distilled water for several hrs, the substrates were flushed with both acetone and iso-propyl alcohol (IPA). The substrates were then subjected to ultrasonic distillation unit containing distilled water for $3 \mathrm{~min}$, and finally were cycled for more than $20 \mathrm{~min}$ in a vapour degreasing unit (Sholet unit) in which iso-propyl alcohol was reflexed continuously, and at this stage the cleaning run was complete.

\subsection{Measuring Techniques}

The refractive indices were measured using both Abbe refractometer with a sodium vapour lamp as the light source emitting the light at a wavelength, $\lambda$, of $589.3 \mathrm{~nm}$ (D line) and ellipsometry using a laser with a wavelength at $632.8 \mathrm{~nm}$.

\subsubsection{Abbe Refractometer Measurements}

The Abbe refractometer was used for measuring refractive indices of silicate 
glasses over a limited operating temperature range. In principle, it consists of a pair of glass prisms with a substrate or a film of liquid between them. Light enters sample from the illuminating prism, get refracted at critical angle at the bottom surface of measuring prism, and then the telescope is used to measure position of the border between bright and light areas. A sample must be well cleaned, polished as flat as possible before placing on the prism surface. Secondly, as an instrument, Abbe refractometer only gives access to the real part of the refractive index.

The refractive indices of silicate glasses were measured by using an Abbe 60 refractometer with a sodium light as the light source at a wavelength $\lambda$ of 589.3 $\mathrm{nm}$ and with temperature-controlled prisms having mono-bromona phthalence as the contact layer (with a refractive index of 1.51) between the silicate glass and the prism of the refractometer. Different Abbe data (scale readings) on silicate glasses was generated by varying the temperature of the glass slide (s) and the prism of the refractometer by circulating hot water through a temperature controlled system over the operating range $278-322 \mathrm{~K}$, which was read from the integral digital display on the instrument. The whole temperature dependent Abbe data was then converted into the refractive index ( $n$ ) data using Abbe utilities software. With good temperature control and use of the micrometer vernier scale, an average accuracy of \pm 0.0008 in the value of refractive index (n) was achieved across the specified temperature measuring range.

\subsubsection{Ellipsometry and Optical Measurements}

Ellipsometry is an optical technique that measures changes in polarization (phase, $\Delta$, and amplitude, $\Psi$ ) of monochromatic light reflecting from matter, and these standard ellipsometric parameters $\Psi$ and $\Delta$ are related to the complex ratio of reflection coefficient for light polarized parallel $\mathbf{p}$ and perpendicular $\mathbf{s}$ to the plane of incidence.

\subsubsection{Basic Principle of Ellipsometry}

The formulation for the manual null ellipsometry is based on Fresnel derived optical equations for any kind of monochromatic light reflecting from a material. Fresnel physical model associated with PCWSW'A version of the most common null ellipsometer configuration (Polarizer-Compensator-Window-SampleWindow-Analyzer) is shown in Figure 1, where Fresnel reflection (amplitude) coefficients for a dielectric substrate relating to $\mathrm{s}$ and $\mathrm{p}$ components can be expressed into a single relation [53] [54].

$$
\rho=\frac{E_{2 p}^{\prime}}{E_{1 p}} / \frac{E_{2 s}^{\prime}}{E_{1 s}}=\left|\frac{r_{p}^{\prime}}{r_{s}^{\prime}}\right| \mathrm{e}^{i \Delta_{s}},
$$

or

$$
\rho_{s}=\tan \psi_{s} \mathrm{e}^{i \Delta_{s}},
$$

where $\Psi_{s}$ and $\Delta_{s}$ are ellipsometric (measurable) angles for a bare substrate, $i$ designates the imaginary unit $(-1)^{1 / 2}$, and the ratio, $\rho_{s}$ is for the dielectric substrate. 


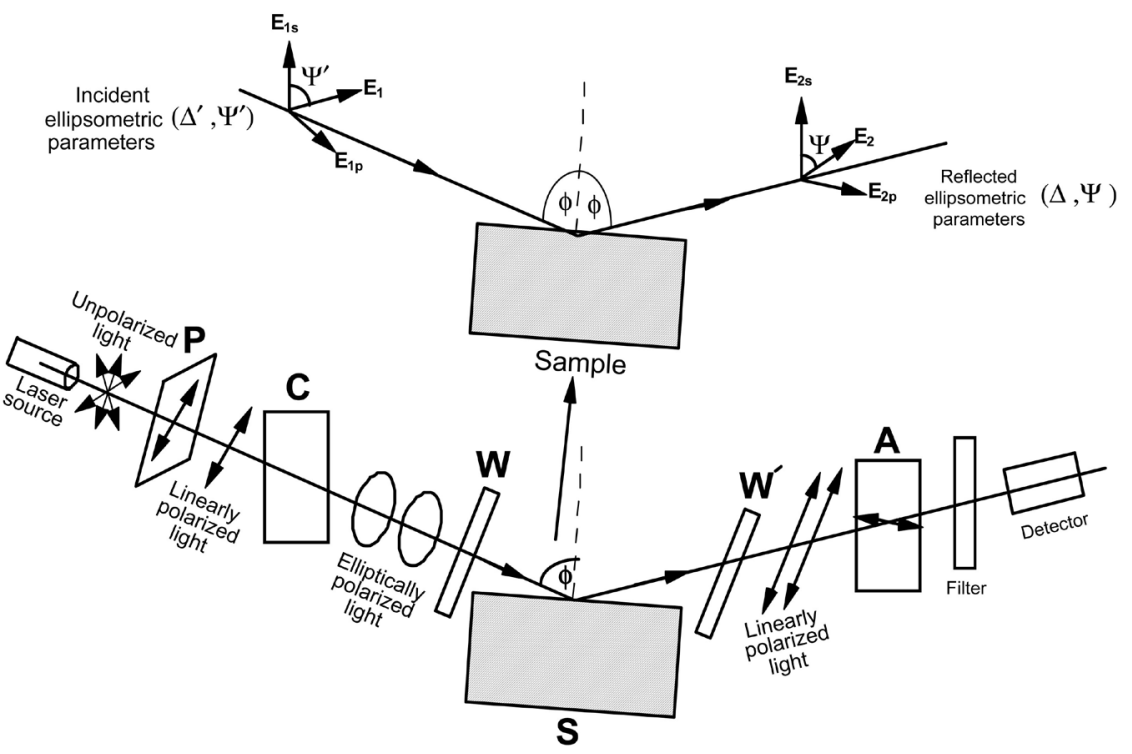

Figure 1. Azimuths and amplitudes of plane-polarized light reflected from a sample (microscopic glass slide) at any angle of incidence.

Refractive index, $n_{s}$ of the substrate is computed from the Expression [54] [55]

$$
n_{s}=\tan \phi_{1}\left\{1-\left(4 \rho_{s} \sin ^{2} \phi_{1}\right)\left(\rho_{s}+1\right)^{-2}\right\}^{1 / 2} .
$$

If the substrate is absorbing, its refractive index will, of course, be complex. The parallel and perpendicular components for Fresnel reflection coefficients, $r_{p}$ and $r_{s}$ were calculated using Fortran 77 version for a single substrate model [55] [56]. The details for the classical ellipsometry inversion formulas are described and reviewed elsewhere [55] [57].

\subsubsection{Operation and Measurement of Ellipsometric Parameters $\Delta$ and $\psi$} High precision single wavelength $(632.8 \mathrm{~nm})$ manual ellipsometry at fixed angle $\left(\sim 60 \sim^{\circ}\right)$ was chosen for in situ heating experiments in order to generate a series of data on the optical constants of silicate glasses in the visible range of solar spectrum. The manual ellipsometer (LQ1PQWSW'AD) which was built up with some modifications in the above version, is shown in Figure 2. A beam of unpolarized monochromatic red light from a He-Ne laser after passing through a quarter-wave plate, $\mathrm{Q}_{1}$ (set at an azimuth $45^{\circ}$ ) was changed into a circularly polarized light. When this circularly polarized light was incident on a polarizer $(\mathrm{P})$, (which is a Glan Thomson prism), only linearly polarized light was allowed to transmit due to total internal reflection occurring inside the prism. Another quarter wave plate, $\mathrm{Q}$ (also known as retarder or compensator, $\mathrm{C}$, and was made out of birefringent mica like $\mathrm{Q}_{1}$ and was fixed with its fast axis at $\pm 45^{\circ}$ to the plane of incidence) which was placed in between the polarizer $(\mathrm{P})$ and the sample (S), changed the approaching polarized light into elliptically polarized light. This polarized light after falling normally (within $2^{\circ}-3^{\circ}$ ) on the fused silica optical window (W) was finally incident on the microscope glass slide at an angle $\sim 60^{\circ}$. It should be specified that the silicate glass slide with its back surface 


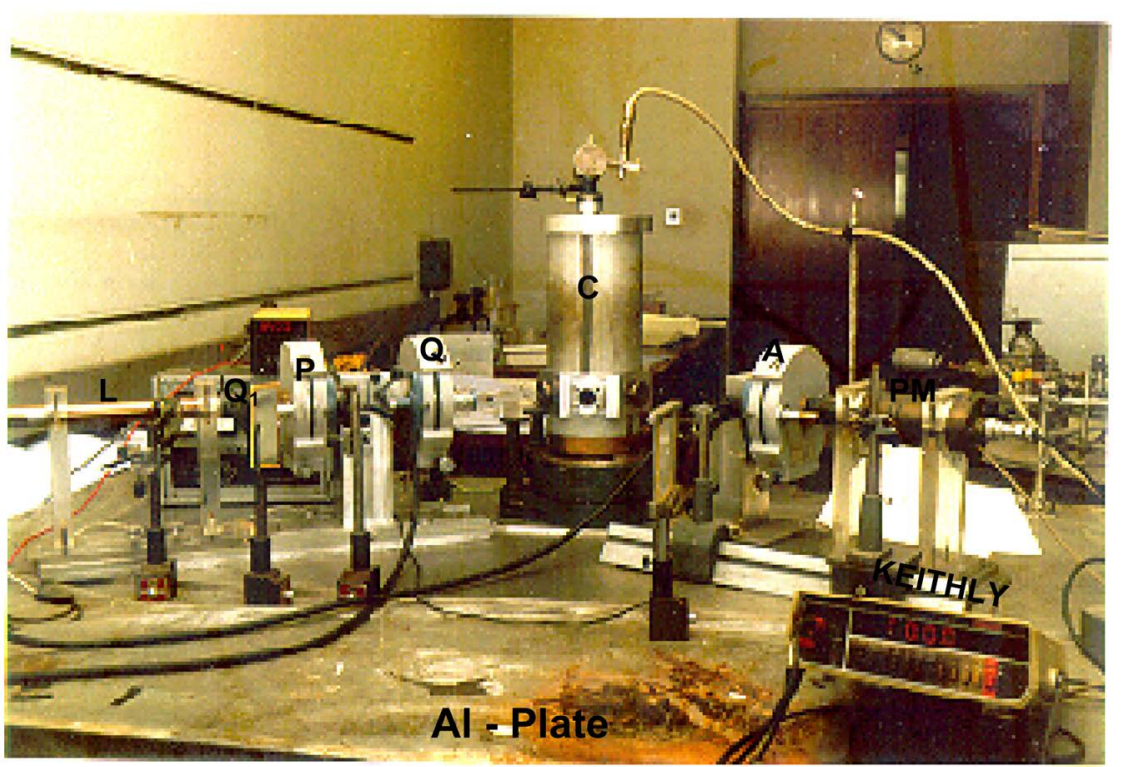

Figure 2. A picture of the apparatus of manual ellipsometer built-up which composed of an aluminum alloy base plate to which ellipsometric components were fixed.

roughened was fixed in a horizontal (or vertical) position inside a vacuum cryostat (positioned on a spectrometer table) and was joined to a temperature controller through a alumel-chromel thermocouple. After reflection from the 7059 glass plate, the polarized light passed through another fused silica optical window $\left(\mathrm{W}^{\prime}\right)$ and was then transmitted through an analyzer (A) (another Glan Thomson prism), and finally reached photomultiplier tube (PM) connected to Keithly to monitor output signal. Since measurements performed with and without the fused silica windows revealed a lot of difference; thus, for the in situ experiments, all the measurements were made with the apparatus fitted with the fused silica optical windows under vacuum.

The precise manual ellipsometric measurements depend on the clear null point at the detector (PM). The angles (P) and (A) were adjusted for minimum output, and were measured as positive counter clockwise from the plane of incidence when looking into the beam. All the scales in the reported apparatus were illuminated to minimize eye strain. The polarizer (P) and the analyzer (A) scale readings were read on graduated circles, which were equipped with two diametrically opposite verniers to cancel the effects of eccentricity. The angle of the analyzer (A) determines the relative amplitude $\left(\Psi^{\circ}\right)$ of the reflected $\mathrm{p}$ and $\mathrm{s}$ waves; and the angle of polarizer (p), when it is on the extinction setting, measures the angle $\left(\Delta^{\circ}\right)$. Once the ellipsometric measurements of $\Delta$ and $\Psi$ are determined, the unknown parameters, real part of the refractive index $(n)$ and index of absorption $(k)$ of an optical substrate, can in principle be calculated using Fortran program.

\section{Experimental Results and Error Analysis}

The relations of ( $\Psi$ and $\Delta)$ to $(\mathrm{P}$ and $\mathrm{A})$ in four zones at extinction settings are 
given by equations [55] [57]

$$
A_{i}=a_{p}\left(\text { or } a_{s}\right)= \pm \Psi_{i}
$$

and

$$
2 p_{i} \pm \frac{\pi}{2}= \pm(-1)^{i} \Delta_{i}
$$

where $i=1,2,3,4$. And $a_{p}$ or $a_{s}$ (depending upon zone) denotes the analyser azimuth angle and $p$ is the polarizer azimuth angle. The quantities to be determined from the experimental data $(\Delta, \Psi)$ using ellipsometric equations are the real part of the refractive index $(n)$, and the extinction coefficient $(k)$ of the acquired glass slide. Ellipsometric Equation (1) was solved using Fortran 77 version. The $(n, k)$ values of different glasses under different temperature conditions were computed directly from the experimental data $(\Delta$ and $\Psi)$. A comparison between manual and auto ellipsometric data is shown in Table 1, which indicates that the manual ellipsometric components were aligned to very high precision. The generated experimental data $(\Delta$ and $\Psi)$ of silicate glasses under different temperature conditions are tabulated in Tables 2-4.

For a clean substrate (silica, soda lime or 7059 glass), a change of $\pm 0.02^{\circ}$ in the measurement of the angle of incidence due to optical window strain gives a net change of $\pm 0.02^{\circ}$ in $\Psi$ value, which gives an error in $n$ of about $\delta n= \pm 0.00041$. Similarly, a change of $\pm 0.04^{\circ}$ in $\Delta$ due to same degree of strain brings a net change in the index of absorption of about $\delta k= \pm 0.0005$. After alignment, the maximum uncertainty in $\Delta$ and $\Psi$ in an open air were found about $\pm 0.02^{\circ}$ and

Table 1. Refractive index of 7059 glass (with back surface roughened by silicon carbide) measured with the data obtained using Abbe refractometer.

\begin{tabular}{cccccc}
\hline Type of instrument used & $\begin{array}{c}\Delta \\
\left(^{\circ}\right)\end{array}$ & $\begin{array}{c}\psi \\
\left(^{\circ}\right)\end{array}$ & $\boldsymbol{n}_{e}$ & $\begin{array}{c}\text { ABBE } \\
\text { Reading }\left({ }^{\circ}\right)\end{array}$ & $\boldsymbol{n}_{\boldsymbol{a}}$ \\
\hline Manual ellipsometer & 0.06 & 5.34 & 1.5296 & & \\
$\begin{array}{c}\text { Automatic ellipsometer } \\
\text { Abbe refractometer }\end{array}$ & 1.96 & 5.04 & 1.5264 & & \\
\hline
\end{tabular}

Table 2. Temperature dependent ellipsometric study of transparent silica plate in comparison with the data obtained using Abbe refractometer.

\begin{tabular}{cccccc}
\hline & \multicolumn{3}{c}{ Manual ellipsometer } & \multicolumn{3}{c}{ ABBE } \\
\hline $\begin{array}{c}\text { Temperature } \\
(\mathrm{K})\end{array}$ & $\Delta$ & $\boldsymbol{(}$ & $\boldsymbol{\circ}_{e}$ & $\begin{array}{c}\text { Reading } \\
\left(^{\circ}\right)\end{array}$ & $\boldsymbol{n}_{a}$ \\
\hline 295.0 & -0.14 & 6.06 & 1.5119 & 24.672 & 1.5276 \\
307.0 & -0.14 & 6.06 & 1.5119 & 24.654 & 1.5275 \\
321.0 & -0.14 & 6.06 & 1.5119 & 24.654 & 1.5274 \\
335.0 & -0.14 & 6.07 & 1.5115 & & \\
373.0 & -0.15 & 6.08 & 1.5111 & & \\
\hline
\end{tabular}


Table 3. Temperature dependent ellipsometric measurements on soda lime glass (with back face roughened by silica carbide) in comparison to data obtained using Abbe refractometer.

\begin{tabular}{|c|c|c|c|c|c|}
\hline \multirow[b]{2}{*}{$\begin{array}{c}\text { Temperature } \\
\text { (K) }\end{array}$} & \multicolumn{3}{|c|}{ Manual ellipsometer } & \multicolumn{2}{|c|}{$\mathrm{ABBE}$} \\
\hline & $\begin{array}{c}\Delta \\
\left({ }^{\circ}\right)\end{array}$ & $\begin{array}{c}\psi \\
\left({ }^{\circ}\right)\end{array}$ & $n_{e}$ & $\begin{array}{c}\text { Reading } \\
\left({ }^{\circ}\right)\end{array}$ & $n_{a}$ \\
\hline 297.0 & -2.42 & 6.18 & 1.5086 & 22.321 & 1.5074 \\
\hline 309.0 & -2.42 & 6.18 & 1.5086 & 22.309 & 1.5072 \\
\hline 321.0 & -2.49 & 6.19 & 1.5082 & 22.288 & 1.5070 \\
\hline 335.0 & -2.53 & 6.20 & 1.5079 & & \\
\hline 375.0 & -2.48 & 6.22 & 1.5072 & & \\
\hline 427.0 & -2.46 & 6.24 & 1.5065 & & \\
\hline
\end{tabular}

Table 4. Temperature dependent ellipsometric measurements on 7059 glass (with back face roughened by silica carbide) in comparison to data obtained using Abbe refractometer.

\begin{tabular}{|c|c|c|c|c|c|}
\hline \multirow[b]{2}{*}{$\begin{array}{c}\text { Temperature } \\
\text { (K) }\end{array}$} & \multicolumn{3}{|c|}{ Manual ellipsometer } & \multicolumn{2}{|c|}{$\mathrm{ABBE}$} \\
\hline & $\begin{array}{c}\Delta \\
\left({ }^{\circ}\right)\end{array}$ & $\begin{array}{c}\psi \\
\left({ }^{\circ}\right)\end{array}$ & $\boldsymbol{n}_{e}$ & $\begin{array}{c}\text { Reading } \\
\left({ }^{\circ}\right)\end{array}$ & $n_{a}$ \\
\hline 295.0 & 0.06 & 5.34 & 1.5296 & 24.747 & 1.5283 \\
\hline 309.0 & 0.06 & 5.34 & 1.5296 & 24.735 & 1.5282 \\
\hline 321.0 & 0.06 & 5.34 & 1.5296 & 24.719 & 1.5281 \\
\hline 337.0 & -0.07 & 5.35 & 1.5292 & & \\
\hline 373.0 & 0.08 & 5.36 & 1.5289 & & \\
\hline 425.0 & 0.05 & 5.37 & 1.5285 & & \\
\hline 473.0 & -0.28 & 5.38 & 1.5281 & & \\
\hline
\end{tabular}

$\pm 0.01^{\circ}$, respectively, and with an in situ manual ellipsometer fitted with fused quartz inlet and exit optical windows, the maximum calibration errors in $\Delta$ and $\Psi$ were about $\pm 0.05^{\circ}$ and $\pm 0.02^{\circ}$ respectively. Nevertheless, four-zone ellipsometric measurements were always made in order to minimize systematic errors.

\section{Results and Discussion}

\subsection{Molar Refraction $\left(R_{m}\right)$, Molar Electronic Polarizability $\left(\alpha_{m e}\right)$, Optical Band Gap $\left(E_{g}\right)$ and Oxide Ion Polarizability $\left[\alpha_{02-}(n)\right.$ and $\left.\alpha_{02-}\left(E_{g}\right)\right]$}

In the first stage, the data on molar refraction $\left(R_{m}\right)$, molar electron polarizability $\left(\alpha_{m e}\right)$, and optical band gap $\left(E_{g}\right)$ of silicate glasses (silica, soda lime, borosilicate 7059) were generated from Tables 2-4 using the following course of action.

Molar refraction $\left(R_{m}\right)$ is related to molar volume $\left(V_{m}\right)$ by the relation [58] [59]

$$
R_{m}=\left(\frac{n^{2}-1}{n^{2}+2}\right) V_{m}
$$


where

$$
V_{m}=\frac{M}{\rho}=\frac{\text { molecular weight }}{\text { mass density }}
$$

Molar electronic polarizability $\left(\alpha_{m e}\right)$ can be related with the molar refractive index by an expression [60] [61]

$$
\alpha_{m e}=\frac{R_{m}}{2.52}
$$

According to Duffy, there also exists a good correlation between molar refraction and the band gap energy $\left(E_{g}\right)$ of the materials (or glasses) and that is given as [60] [61]

$$
R_{m}=V_{m}\left[1-\sqrt{\frac{E_{g}}{20}}\right]
$$

The required data on the above optical parameters was obtained using Equations (5)-(8).

In the second stage, the following models were used to obtain other properties. The electronic oxide ion polarizabilities based on refractice index and optical band gap $\alpha_{02-}(n)$ and $\alpha_{02-}\left(E_{g}\right)$ for the silicate glasses were determined using their reported refractive indices $(n)$ and the obtained optical band gaps $\left(E_{g}\right)$. The oxide ion polarizability based on refractive index was calculated using relation as reported by Meen and Bhatia [62] [63]

$$
\alpha_{02-}(n)=\left[\left(\frac{V_{m}}{2.52}\right)\left(\frac{n^{2}-1}{n^{2}+2}\right)-\sum \alpha_{i}\right] q^{-1} .
$$

where $V_{m}$ is molar volume; $n$, the refractive index; $E_{g}$ expresses the optical band gap of the glass; $\sum \alpha_{i}$ denotes the sum of molar cation polarizabilities of all constituents, and $q^{-1}$ is the inverse of total number of oxide ions in the chemical formula of the oxide.

In the case of silica glass, the physical parameters like $V_{m}, \sum \alpha_{i}$, and $q^{-1}$ involved in the Equation (9) are given and/or measured as follows.

$$
V_{m}=\frac{\text { Molecular weight }}{\text { Mass density }}=\frac{60.08}{2.65}=22.672 \mathrm{~mol}^{-1} / \mathrm{cm}^{-3} ; \frac{V_{m}}{2.52}=8.997 ;
$$

the cation polarizability for $\mathrm{SiO}_{2}, \sum \alpha_{i}=0.033 \AA^{3}\{\mathrm{~A} 41, \mathrm{~A} 42\}$; the inverse of number of oxide ions in $\mathrm{SiO}_{2}, q^{-1}=0.504 \times 10^{-24} \mathrm{~cm}^{3} /$ ions . It should be noted that the value of " $q$ " is the number of moles of oxide ions in $\mathrm{SiO}_{2}$ multiplied by Avogado numbers. Substituting all these values into Equation (9), the Equation (9) is reshaped as

$$
\alpha_{02-}(n)=\left[8.997 \times\left(\frac{n^{2}-1}{n^{2}+2}\right)-0.033\right] \times 0.504 \times 10^{-24} .
$$

The values of $n$ and $\alpha_{02-}(n)$ for a silica glass [using Equation (10)] were measured from 1.5119 to 1.5111 and 1.3438 to 1.3420 , respectively over the temperature range $295-373 \mathrm{~K}$ using ellipsometer at $\lambda=633.8 \mathrm{~nm}$. The values of $n$ and 
$\alpha_{\mathrm{o2}-}(n)$ relating to silica glass were respectively measured from 1.5276 to 1.5274 and 1.3786 to1.3782, respectively over the temperature range 297 - $322 \mathrm{~K}$ using Abbe refractometer at $\lambda=589.3 \mathrm{~nm}$.

In the case of soda lime silicate glass, we have

$V_{m}=\frac{\text { Molecular weight }}{\text { Mass density }}=\frac{59.34}{2.50}=23.74 \mathrm{~mol}^{-1} / \mathrm{cm}^{-3} ; \frac{V_{m}}{2.52}=9.42$;

$\sum \alpha_{i}=0.1153 \AA^{3} ; q^{-1}=0.593 \times 10^{-24} \mathrm{~cm}^{3} /$ ions . Substituting all these values into Equation (9), we obtain new relation as:

$$
\alpha_{02-}(n)=\left[9.42 \times\left(\frac{n^{2}-1}{n^{2}+2}\right)-0.1153\right] \times 0.593 \times 10^{-24}
$$

The values of $n$ and $\alpha_{02-}(n)$ for a soda lime glass [using Equation (11)] were measured from 1.5086 to 1.5065 and 1.6012 to 1.5954 , respectively over the temperature range $295-373 \mathrm{~K}$ using ellipsometer at $\lambda=633.8 \mathrm{~nm}$. The values of $n$ and $\alpha_{02-}(n)$ relating to silica glass were respectively measured from 1.5074 to 1.5070 and 1.5983 to1.5969 over the temperature range 298 - $322 \mathrm{~K}$ using Abbe refractometer at $\lambda=589.3 \mathrm{~nm}$.

In the case of borosilicate 7059 glass, we have

$V_{m}=\frac{\text { Molecular weight }}{\text { Mass density }}=\frac{62.27}{2.76}=22.562 \mathrm{~mol}^{-1} / \mathrm{cm}^{-3} ; \frac{V_{m}}{2.52}=8.953$;

$\sum \alpha_{i}=0.0448 \AA^{3} ; q^{-1}=0.524 \times 10^{-24} \mathrm{~cm}^{3} /$ ions . After substituting all these values into Equation (9), we have new equation as

$$
\alpha_{02-}(n)=\left[8.953 \times\left(\frac{n^{2}-1}{n^{2}+2}\right)-0.0448\right] \times 0.524 \times 10^{-24}
$$

The values of $n$ and $\left(\alpha_{02-}(n)\right)$ for a borosilicate 7059 glass [using Equation (12)] were measured from 1.5296 to 1.5281 and 1.4329 to 1.4288 , respectively over the temperature range $295-473 \mathrm{~K}$ using ellipsometer at $\lambda=633.8 \mathrm{~nm}$. The values of $n$ and $\left(\alpha_{02-}(n)\right)$ relating to borosilicate 7059 glass were respectively measured from 1.5283 to 1.5281 and 1.4297 to 1.4287 over the temperature range 297 - $322 \mathrm{~K}$ using Abbe refractometer at $\lambda=589.3 \mathrm{~nm}$.

Similarly, optical band gap based oxide ion polarizability of any silicate glass can be calculated using the following relation [63] [64]

$$
\alpha_{02-}\left(E_{g}\right)=\left[\left(\frac{V_{m}}{2.52}\right)\left(1-\sqrt{\frac{E_{g}}{20}}\right)-\sum \alpha_{i}\right] q^{-1}
$$

Using all the values of the optical parameters as mentioned above, the respective relations regarding silica, soda lime, and borosilicate 7059 glasses are printed as:

$$
\begin{aligned}
& \alpha_{02-}\left(E_{g}\right)=\left[8.997 \times\left(1-\sqrt{\frac{E_{g}}{20}}\right)-0.033\right] \times 0.504 \times 10^{-24} \\
& \alpha_{02-}\left(E_{g}\right)=\left[9.42 \times\left(1-\sqrt{\frac{E_{g}}{20}}\right)-0.1153\right] \times 0.593 \times 10^{-24}
\end{aligned}
$$




$$
\alpha_{02-}\left(E_{g}\right)=\left[8.953 \times\left(1-\sqrt{\frac{E_{g}}{20}}\right)-0.0448\right] \times 0.524 \times 10^{-24}
$$

In the case of silica glass, the optical band gap $\left(E_{g}\right)$ using Equation (14) was measured as $9.8 \mathrm{eV}$ at room temperature and it increased to 9.81 at $373 \mathrm{~K}$. The oxide ion polarizability of silica glass $\alpha_{02-}\left(E_{g}\right)$ using Equation (14) was measured from 1.3427 to 1.3408 over the temperature range 295 - $373 \mathrm{~K}$ using ellipsometer at $\lambda=633.8 \mathrm{~nm}$. The values of optical band gap relating to silica glass were measured from 9.59 to $9.592 \mathrm{eV}$ over the temperature range 297 - $322 \mathrm{~K}$ using Abbe refractometer at $\lambda=589.3 \mathrm{~nm}$, and the values of $\alpha_{02-}\left(E_{g}\right)$ relating to silica glass were measured from 1.3766 to 1.3764 using Abbe refractometer over the same temperature range and at the same wavelength range.

For soda glass, $E_{g}$ was measured from 9.845 to $9.88 \mathrm{eV}$ over the temperature range 295 - $427 \mathrm{~K}$ using ellipsometer at $\lambda=633.8 \mathrm{~nm}$, and the oxide ion polarizability of soda lime silicate glass using Equation (15) was measured from 1.6014 to 1.5941 using ellipsometer over the same temperature range and at the same wavelength. The values of optical band gap and $\alpha_{02-}\left(E_{g}\right)$ relating to soda lime silicate glass were measured respectively from 9.862 to $9.870 \mathrm{eV}$ and from 1.5991 to 1.5972 over the temperature range $298-322 \mathrm{~K}$ using Abbe refractometer at $\lambda$ $=589.3 \mathrm{~nm}$. Similarly, the values of optical band gap and $\alpha_{\mathrm{o} 2-}\left(E_{g}\right)$ relating to borosilicate 7059 glass [using Equations (8) and (16)] were measured respectively from 9.56 to $9.58 \mathrm{eV}$ and from 1.4223 to 1.4193 over the temperature range 295 $473 \mathrm{~K}$ using elipsometer at $\lambda=633.8 \mathrm{~nm}$. The values of optical band gap $\left(E_{g}\right)$ and $\alpha_{02-}\left(E_{g}\right)$ relating to 7059 glass were measured respectively from 9.574 to $9.58 \mathrm{eV}$ and from 1.4195 to 1.4191 over the temperature range 297 - $322 \mathrm{~K}$ using Abbe refractometer at $\lambda=589.3 \mathrm{~nm}$. The complete generated temperature dependent data on the oxide ion polarizability regarding investigated silicate glasses are included in Tables 5-7, and are plotted in Figure 3, Figure 5 and Figure 7 . It

Table 5. The various physical properties of silica glass: $n, R_{m}, E_{g}, \alpha_{m e}, \alpha_{\mathrm{O} 2-}(n)$ and $\alpha_{\mathrm{O} 2-}\left(E_{g}\right)$, $A(n)$ and $A\left(E_{g}\right)$ [all the symbols are defined in the text] using ellipsometer and Abbe refractometer.

\begin{tabular}{cccccccccc}
\hline \multicolumn{7}{c}{ Ellipsometric } \\
\hline $\begin{array}{c}\text { Temperature } \\
(\mathrm{K})\end{array}$ & $\boldsymbol{n}$ & $\boldsymbol{R}_{\boldsymbol{m}}$ & $\begin{array}{c}E_{g} \\
(\mathrm{eV})\end{array}$ & $\begin{array}{c}\boldsymbol{\alpha}_{m e} \\
\left(\times 10^{-24} \mathrm{~cm}^{3}\right)\end{array}$ & $\boldsymbol{\alpha}_{\text {O2- }}(\boldsymbol{n})$ & $\boldsymbol{\alpha}_{\text {O2- }}\left(E_{g}\right)$ & $\boldsymbol{A}(\boldsymbol{n})$ & $\boldsymbol{A}\left(E_{g}\right)$ \\
\hline 295.0 & 1.5119 & 6.802 & 9.80 & 2.6992 & 1.3438 & 1.3427 & 0.4272 & 0.4262 \\
307.0 & 1.5119 & 6.802 & 9.80 & 2.6992 & 1.3438 & 1.3427 & 0.4272 & 0.4262 \\
321.0 & 1.5119 & 6.802 & 9.80 & 2.6992 & 1.3438 & 1.3427 & 0.4272 & 0.4262 \\
335.0 & 1.5115 & 6.797 & 9.80 & 2.6972 & 1.3428 & 1.3427 & 0.4262 & 0.4259 \\
373.0 & 1.5111 & 6.793 & 9.81 & 2.6959 & 1.3420 & 1.3408 & 0.4255 & 0.4245 \\
\hline & & & & $\mathrm{Abbe}$ & & & \\
\hline 297.0 & 1.5276 & 6.976 & 9.590 & 2.7683 & 1.3786 & 1.3766 & 0.4586 & 0.4569 \\
308.0 & 1.5275 & 6.976 & 9.590 & 2.7683 & 1.3786 & 1.3766 & 0.4586 & 0.4569 \\
322.0 & 1.5274 & 6.974 & 9.592 & 2.7675 & 1.3782 & 1.3764 & 0.4582 & 0.4567 \\
\hline
\end{tabular}




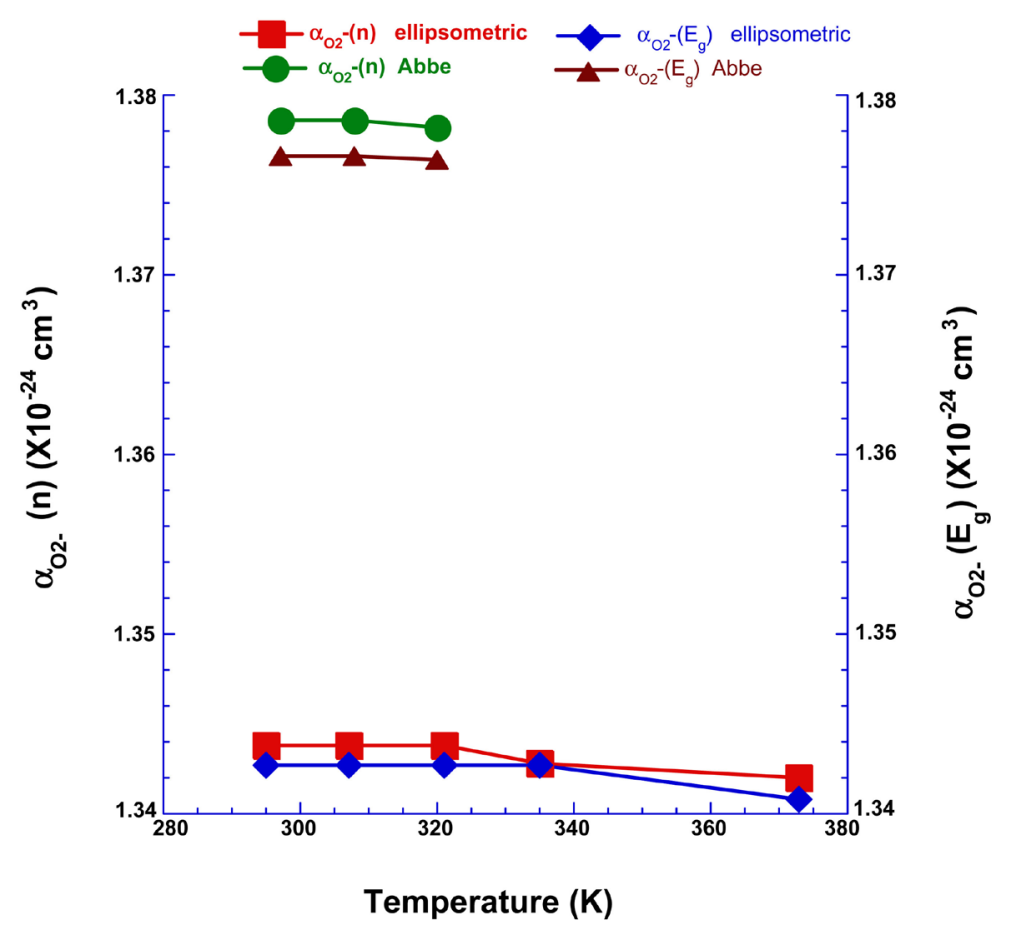

Figure 3. Refractive index based oxide ion polarizability, $\alpha_{\mathrm{O} 2-}(n)$ and optical band gap based oxide ion polarizability, $\alpha_{\mathrm{O} 2-}\left(E_{g}\right)$ of silica glass against temperature using ellipsometry and Abbe refractometer.

Table 6. The various physical properties of soda lime glass: $n, R_{m}, E_{g}, \alpha_{m e}, \alpha_{\mathrm{O} 2-}(n)$ and $\alpha_{\mathrm{O} 2-}$ $\left(E_{g}\right), A(n)$ and $A\left(E_{g}\right)$ [all the symbols are defined in the text] using ellipsometer and Abbe refractometer.

\begin{tabular}{cccccccccc}
\hline & \multicolumn{7}{c}{ Ellipsometric } \\
\hline $\begin{array}{c}\text { Temperature } \\
(\mathrm{K})\end{array}$ & $\boldsymbol{n}$ & $\boldsymbol{R}_{\boldsymbol{m}}$ & $\begin{array}{c}E_{g} \\
(\mathrm{eV})\end{array}$ & $\begin{array}{c}\boldsymbol{\alpha}_{m e} \\
\left(\times 10^{-24} \mathrm{~cm}^{3}\right)\end{array}$ & $\boldsymbol{\alpha}_{\text {O2- }}(\boldsymbol{n})$ & $\boldsymbol{\alpha}_{\text {O2- }}\left(E_{g}\right)$ & $A(\boldsymbol{n})$ & $\boldsymbol{A}\left(E_{g}\right)$ \\
\hline 295.0 & 1.5086 & 7.084 & 9.85 & 2.8110 & 1.6012 & 1.6014 & 0.6271 & 0.6269 \\
309.0 & 1.5086 & 7.084 & 9.85 & 2.8110 & 1.6012 & 1.6014 & 0.6271 & 0.6269 \\
321.0 & 1.5082 & 7.079 & 9.85 & 2.8090 & 1.6001 & 1.6003 & 0.6264 & 0.6261 \\
335.0 & 1.5079 & 7.075 & 9.86 & 2.8075 & 1.5992 & 1.5986 & 0.6257 & 0.6254 \\
375.0 & 1.5072 & 6.067 & 9.87 & 2.8044 & 1.5972 & 1.5962 & 0.6244 & 0.6237 \\
427.0 & 1.5065 & 7.058 & 9.88 & 2.8010 & 1.5954 & 1.5941 & 0.6232 & 0.6224 \\
\hline & & & & $\mathrm{Abbe}$ & & & \\
\hline 298.0 & 1.5074 & 7.070 & 9.862 & 2.8060 & 1.5983 & 1.5991 & 0.6251 & 0.6256 \\
308.0 & 1.5072 & 7.067 & 9.865 & 2.8040 & 1.5971 & 1.5974 & 0.6244 & 0.6246 \\
322.0 & 1.507 & 7.065 & 9.870 & 2.8036 & 1.5969 & 1.5972 & 0.6242 & 0.6243 \\
\hline
\end{tabular}

should be noted that the values of $n$ and $\left(\alpha_{02-}(n)\right)$ measured from both optical techniques (Ellipsometry and Abbe 60 refractometer) showed agreeable consistency. The interpretation of this data along with the data on optical basicity is given in the next section. 
Table 7. The various physical properties of 7059 glass: $n, R_{m}, E_{g}, \alpha_{m e}, \alpha_{\mathrm{O} 2-}(n)$ and $\alpha_{\mathrm{O} 2-}\left(E_{g}\right)$, $A(n)$ and $A\left(E_{g}\right)$ [all the symbols are defined in the text] using ellipsometer and Abbe refractometer.

\begin{tabular}{|c|c|c|c|c|c|c|c|c|}
\hline & \multicolumn{8}{|c|}{ Ellipsometric } \\
\hline $\begin{array}{c}\text { Temperature } \\
\text { (K) }\end{array}$ & $n$ & $R_{m}$ & $\begin{array}{c}E_{g} \\
(\mathrm{eV})\end{array}$ & $\begin{array}{c}a_{m e} \\
\left(\times 10^{-24} \mathrm{~cm}^{3}\right)\end{array}$ & $\alpha_{\mathrm{O} 2-}(n)$ & $\alpha_{\mathrm{O} 2-}\left(E_{g}\right)$ & $A(n)$ & $A\left(E_{g}\right)$ \\
\hline 295.0 & 1.5296 & 7.012 & 9.560 & 2.7830 & 1.4329 & 1.4223 & 0.5045 & 0.4958 \\
\hline 309.0 & 1.5296 & 7.012 & 9.560 & 2.7830 & 1.4329 & 1.4223 & 0.5045 & 0.4958 \\
\hline 321.0 & 1.5296 & 7.012 & 9.560 & 2.7830 & 1.4329 & 1.4223 & 0.5045 & 0.4958 \\
\hline 337.0 & 1.5296 & 7.007 & 9.563 & 2.7810 & 1.4318 & 1.4219 & 0.5037 & 0.4955 \\
\hline 373.0 & 1.5089 & 7.005 & 9.570 & 2.7790 & 1.4308 & 1.4209 & 0.5028 & 0.4947 \\
\hline 425.0 & 1.5085 & 7.001 & 9.572 & 2.7781 & 1.4303 & 1.4205 & 0.5023 & 0.4943 \\
\hline \multirow[t]{2}{*}{473.0} & 1.5281 & 6.994 & 9.580 & 2.7753 & 1.4288 & 1.4193 & 0.5012 & 0.4933 \\
\hline & \multicolumn{8}{|c|}{ Abbe } \\
\hline 297.0 & 1.5283 & 6.9982 & 9.574 & 2.7770 & 1.4297 & 1.4195 & 0.5018 & 0.4935 \\
\hline 307.0 & 1.5282 & 6.9959 & 9.580 & 2.7762 & 1.4293 & 1.4191 & 0.5017 & 0.4932 \\
\hline 322.0 & 1.5281 & 6.9936 & 9.580 & 2.7752 & 1.4288 & 1.4191 & 0.5010 & 0.4930 \\
\hline
\end{tabular}

\subsection{Optical Basicity}

The theoretical optical basicity $\left(A_{t h}\right)$ for the materials under study can be measured using the relation [62] [63]

$$
A_{t h}=\sum x_{i} A_{i},
$$

where $A_{i}$ is the individual optical basicity of each of the constituting oxides, and $x_{i}$ is the molar concentration of the respective constituent oxide.

The optical basicity can be alternatively calculated from the relationship of basicity and molar refractivity. Duffy [65] explained that there is an intrinsic relationship between oxide ion polarizability $\alpha_{\mathrm{O} 2-}$ and optical basicity of the glass medium by the following correlation.

This equation indicates that the optical basicity increases with increasing oxide ion polarizability. The newly generated data of optical basicity using Equation (18) is shown in Tables 5-7 and plotted in Figure 4, Figure 6 and Figure 8. The values of optical basicity can also be calculated by the data of oxide ion polarizability $\alpha_{\mathrm{O} 2-}\left(E_{g}\right)$ [generated by optical band gap $\left(E_{g}\right)$ values] using the relation suggested by Duffy [65]

$$
A\left(E_{g}\right)=1.67\left[1-\frac{1}{\alpha_{\mathrm{O} 2-}\left(E_{g}\right)}\right] .
$$

In the first step, the values of optical basicity (refractive index based) of all investigated silicate glasses are calculated theoretically and are printed as $\mathbf{0 . 4 8}$, $\mathbf{0 . 5 8 2 5}$, and $\mathbf{0 . 5 0 8 5}$ for the silica glass, soda lime glass, and borosilicate 7059 silicate glass, respectively. The values of optical basicity of all constituting oxides 


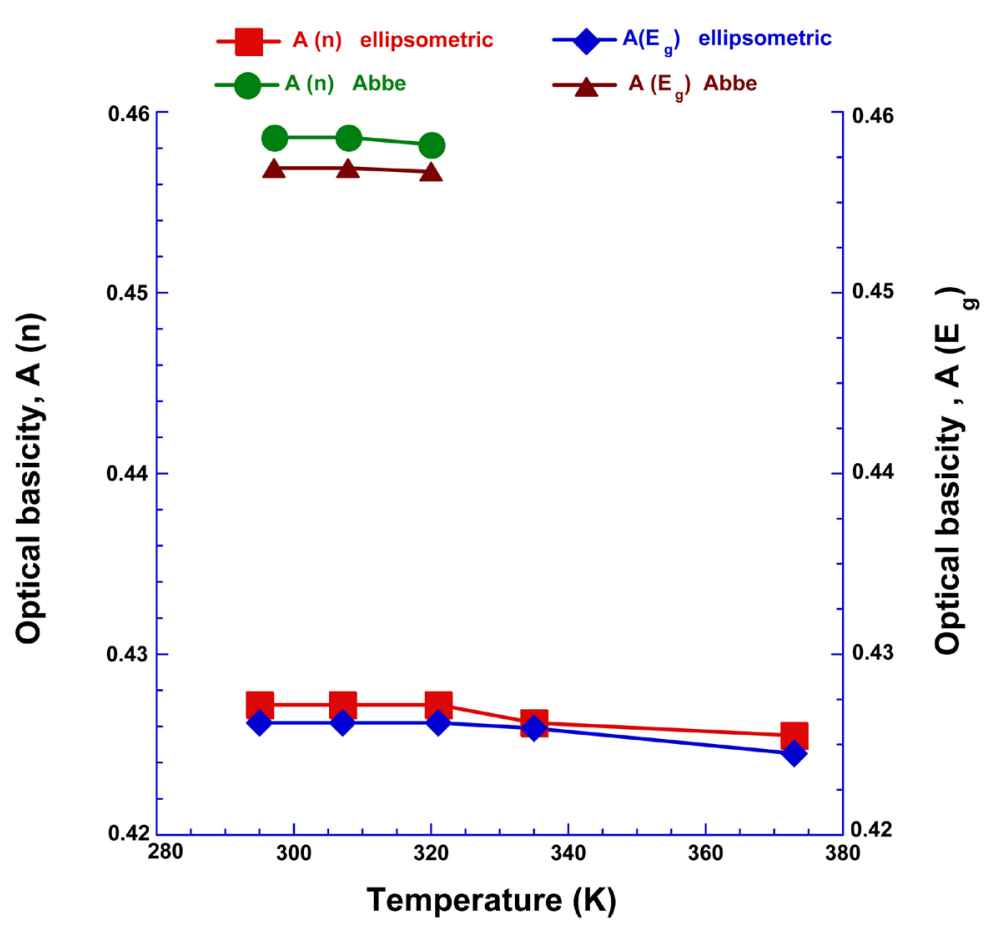

Figure 4. Refractive index based optical basicity, $A(n)$ and optical band gap based optical basicity, $A\left(E_{g}\right)$ of silica glass versus temperature using ellipsometry and Abbe refractometer.

have been taken from the references [62] [64]. In the second step, by the help of temperature dependent refractive index data (both ellipsometric and Abbe: Tables 2-4), we have measured the optical basicity values $\{A(n)\}$ and $\left\{A\left(E_{g}\right)\right\}$ of investigated silicate glasses using the Equations (18) and (19), and the obtained results are included in Tables 5-7 and are plotted in Figure 4, Figure 6 and Figure 8. The measured optical basicity values of investigated glasses at room temperature are given as $A(n)=\mathbf{0 . 4 2 7 2}, \mathbf{0 . 6 2 7 1}, 0.5045$ for the silica, soda lime silicate, and borosilicate 7059 glasses, respectively (using ellipsometry), and $A$ $(n)=0.4586,0.6251,0.5018$ for the silica, soda lime silicate, and borosilicate 7059 glasses, respectively using Abbe refractometer. It should be noticed that the experimental values of optical basicity $A(n)$ are very close to the theoretically calculated optical basicity $\left(A_{t h}\right)$ values regarding silica, soda lime, and borosilicate 7059 glasses.

As shown in Tables 5-7, refractive index $(n)$ is decreased from 1.5119 to 1.5111 and optical band gap $\left(E_{g}\right)$ of silica glass is increased from 9.8 to $9.81 \mathrm{eV}$ over the temperature range 295 to $373 \mathrm{~K}$ using ellipsometer; and the n-value is decreased from 1.5276 to 1.5274 and $E_{g}$ is increased from 9.59 to $9.592 \mathrm{eV}$ over the temperature range 297 to $322 \mathrm{~K}$ using Abbe refractometer. In the case of soda lime silicate glass, refractive index $(n)$ is decreased from 1.5086 to 1.5065 and optical band gap $\left(E_{g}\right)$ of soda lime glass is increased from 9.845 to $9.88 \mathrm{eV}$ over the temperature range 295 to $427 \mathrm{~K}$ using ellipsometer; and the $n$-value is decreased from 1.5074 to 1.5070 and $E_{g}$ is increased from 9.862 to $9.870 \mathrm{eV}$ over 
the temperature range 298 to $322 \mathrm{~K}$ using Abbe refractometer. The refractive index $(n)$ associated with borosilicate 7059 glass is decreased from 1.5296 to 1.5281 and optical band gap $\left(E_{g}\right)$ is increased from 9.56 to $9.88 \mathrm{eV}$ over the temperature range 295 to $473 \mathrm{~K}$ using ellipsometer; and the $\mathrm{n}$-value is decreased from 1.5283 to 1.5281 and $E_{g}$ is increased from 9.574 to $9.58 \mathrm{eV}$ over the temperature range 297 to $322 \mathrm{~K}$ using Abbe refractometer.

Figure 4, Figure 6 and Figure 8 also show that refractive index based optical basicity is decreased from 0.4272 to 0.4255 and $A\left(E_{g}\right)$ is decreased from 0.4262 to 0.4245 (silica glass) over the temperature range 295 - $373 \mathrm{~K}$ using ellipsometer; $A(n)$ is decreased from 0.4586 to 0.4582 and $A\left(E_{g}\right)$ is decreased from 0.4569 to 0.4567 over the temperature range $297-322 \mathrm{~K}$ using Abbe refractometer. In the case of soda lime silicate, $A(n)$ is decreased from 0.6271 to 0.6232 and $A\left(E_{g}\right)$ is decreased from 0.6269 to 0.6224 over the temperature range 295 - $427 \mathrm{~K}$ using ellipsometer; $A(n)$ is decreased from 0.6251 to 0.6242 and $A\left(E_{g}\right)$ is decreased from 0.6256 to 0.6243 over the temperature range 298 - $322 \mathrm{~K}$ using Abbe refractometer. The value of $A(n)$ associated with borosilicate 7059 glass is decreased from 0.5045 to 0.5012 and $A\left(E_{g}\right)$ is decreased from 0.4958 to 0.4933 over the temperature range 295 - $473 \mathrm{~K}$ using ellipsometer; $A(n)$ is decreased from 0.5018 to 0.5010 and $A\left(E_{g}\right)$ is decreased from 0.4935 to 0.4930 over the temperature range 297 - $322 \mathrm{~K}$ using Abbe refractometer.

Here, let me interpret the reported data on oxide ion polarizability and optical basicity regarding silicate glasses briefly as follows.

Figures 3-8 show that the optical band gap $\left(E_{g}\right)$ value of silicate glasses is increased as temperature is increased. Such an increase can be explained by suggesting that the non-bridging oxygen (NBO) ions content decreases and leading to an increase in the value of $E_{g}$. Generally, the less polarizable cations in the glass matrix does not cause effective retardation of the light propagation through the vitreous network to lead to an increase in the refractive index $(n)$. It is also very clear from Figure 3, Figure 5 and Figure 7 that both of refractive index and energy band gap based oxide ion polarizability have the same decreasing trend as the temperature increases. The decreasing trend occurs due to decreasing amount of non-bridging oxygen (NBO), and that trend is due to small single bond strength and small polarizability associated with the silicate glass system.

Next, the disagreement between $A_{t h}$ and experimental basicity value might occur as a result of significant structural changes such as change in coordination number. It can be clearly seen from the obtained values of optical basicity (Figure 4, Figure 6 and Figure 8) that the optical basicity on the basis of $n$ and $E_{g}$ is decreased as temperature is increased. The decreasing trend in both optical basicity values indicates that the glasses prepared are acidic in nature and have very small amount of polarizability. The decrease in the optical basicity values (due to increase in temperature) is due to decreasing negative charge on the oxygen atoms that lead to decreasing covalency in the cation-oxygen bonding associated with the silicate glasses [66]. 


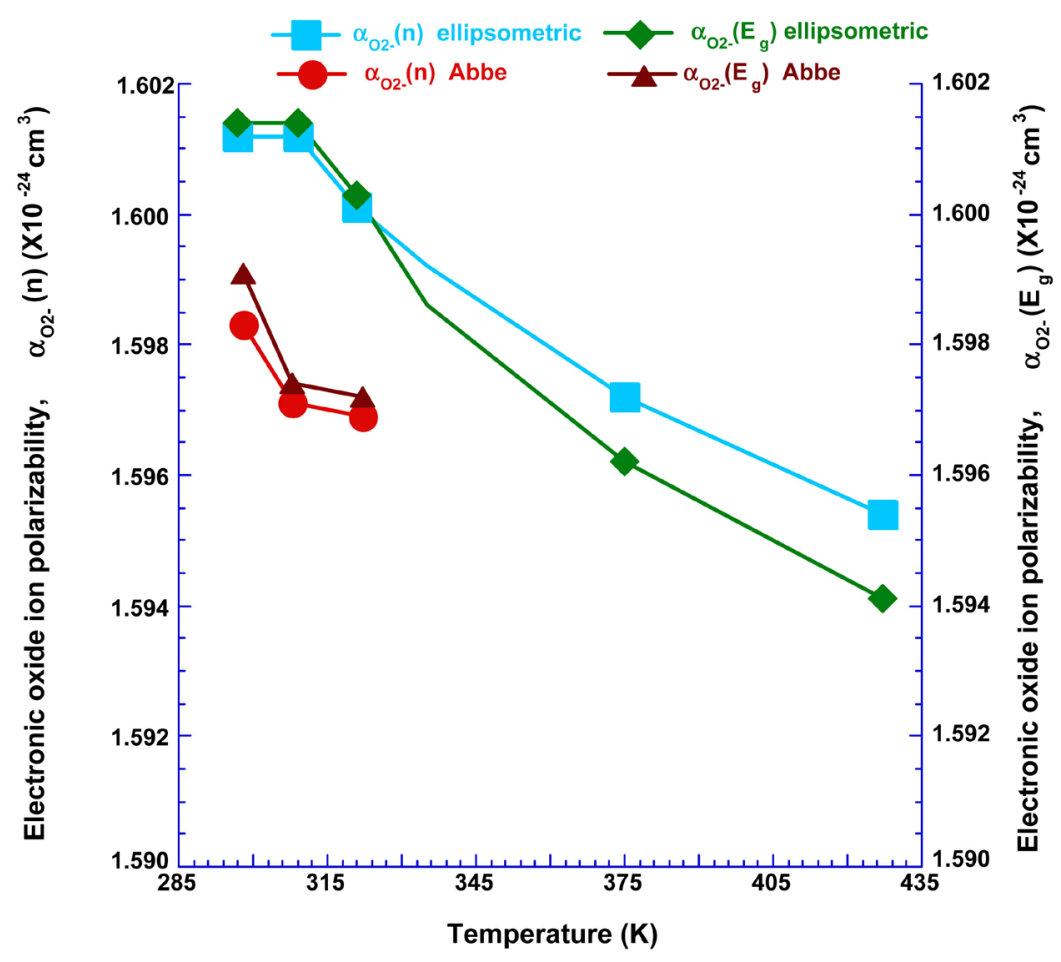

Figure 5. The plot of refractive index based oxide ion polarizability, $\alpha_{\mathrm{O} 2-}(n)$ and optical band gap based oxide ion polarizability, $\alpha_{\mathrm{O} 2-}\left(E_{g}\right)$ of soda lime glass against temperature using ellipsometry and Abbe refractometer.

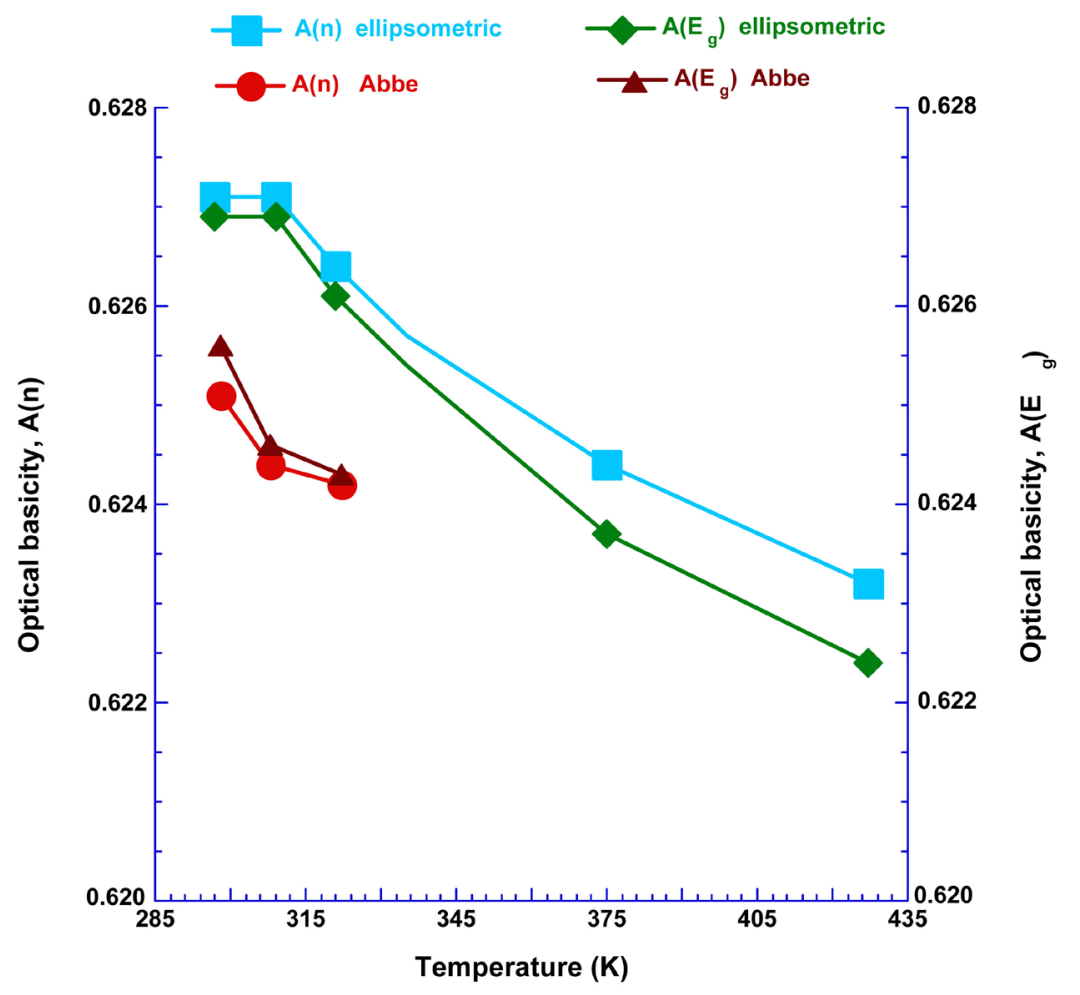

Figure 6. The plot of refractive index based optical basicity, $A(n)$ and optical band gap based optical basicity, $A\left(E_{g}\right)$ of soda lime glass versus temperature using ellipsometry and Abbe refractometer. 


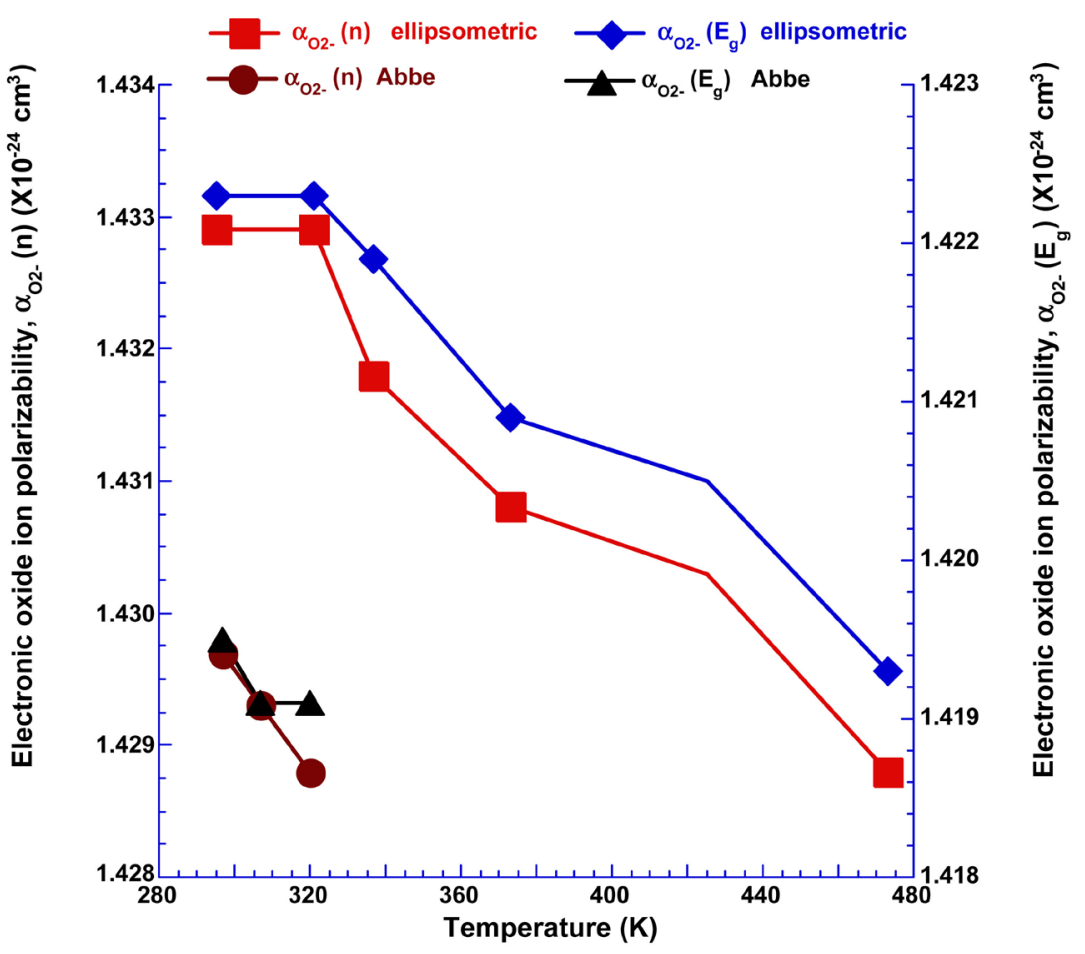

Figure 7. The plots of refractive index based oxide ion polarizability, $\alpha_{\mathrm{O} 2-}(n)$ and optical band gap based oxide ion polarizability, $\alpha_{\mathrm{O} 2-}\left(E_{g}\right)$ of 7059 glass against temperature using ellipsometer and Abbe refractometer.

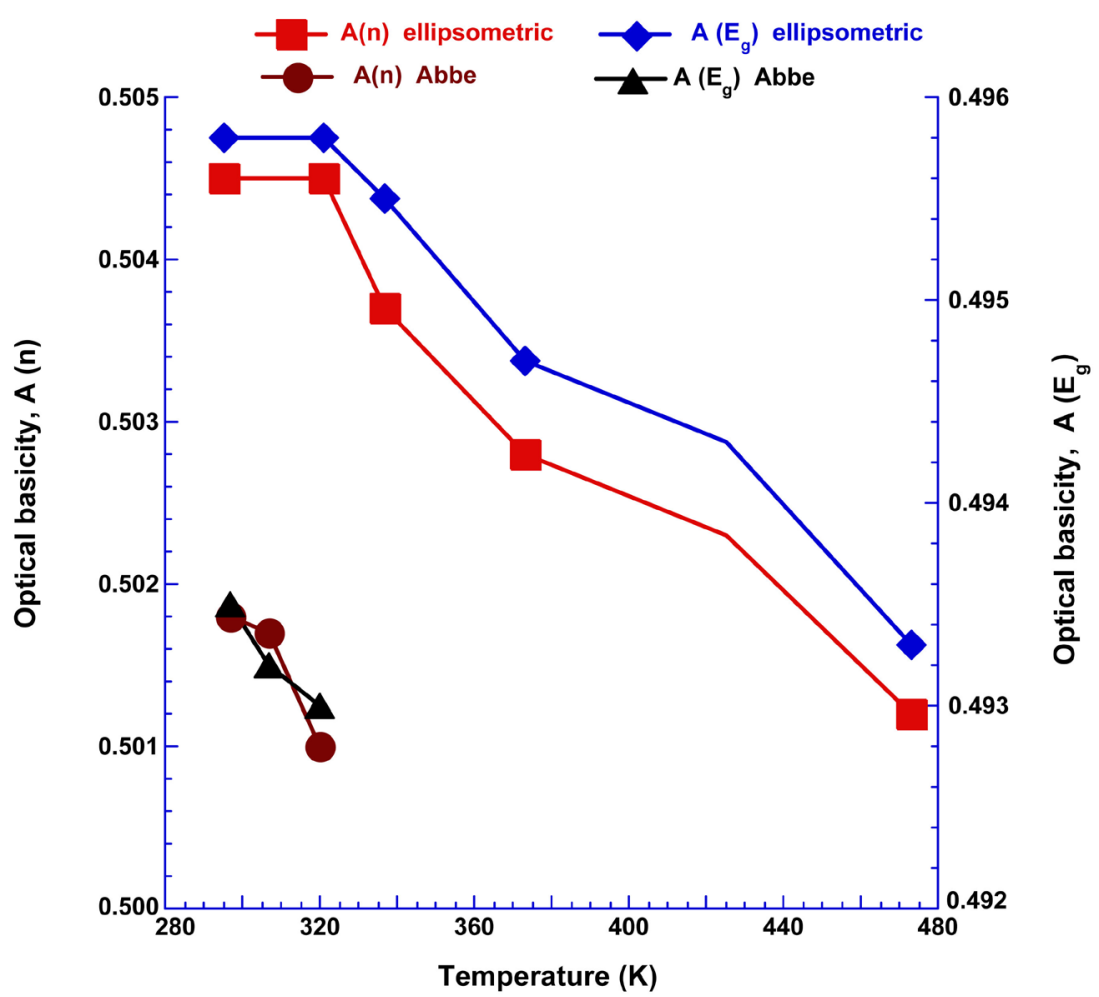

Figure 8. The plots of refractive index based optical basicity, $A(n)$ and optical band gap based optical basicity, $A\left(E_{g}\right)$ of 7059 glass against temperature using ellipsometry and Abbe refractometer. 
So low values of optical basicity and of oxide ion polarizability [67] [68] [69] suggest that the silicate glasses are not novel glasses (optical functional glasses) for non-linear optical (NLO) devices or for three dimensional displays [70] [71] [72] [73] and biological systems [74]. However, any change of oxygen bonding in the glass network, for instance, the formation of non-bridging oxygen, can change the characteristic absorption edge leading to an increase in both the electronic and oxide ion polarizability in the network for NLO applications.

\subsection{Oxide Ion Polarizability, Optical Basicity and Electronegativity}

Since any methodology such as atomic force microscopy for the purpose to evaluate the electronegativity of any material (or any chemical compound) cannot take into account the real crystal structure of the material, i.e., it does not estimate the real distances of the chemical bonds in the structure under consideration. In contrast oxide ion polarizability and optical basicity are based on the experimentally obtained materials constants such as refractive index or energy gap which closely are related to the real electronic structure of the oxides. So, we have measured the values of electronegativity of silicate glasses by using the experimental data on oxide ion polarizability and optical basicity being generated by the reported data on ellipsometer and Abbe refractometer over the temperature range $295-473 \mathrm{~K}$.

There are many empirical models in the literature [75] [76] [77] [78] [79] which relate electronegativity to oxide ion polarizability or to optical basicity of a material, but the values of electronegativity, or of oxide ion polarizability $\left[\alpha_{02}\right.$ $(n)]$ or of optical basicity of silicate glasses calculated by most of the models seem to be too large. So, we have followed the following approach for this problem.

According to Reddy et al. [76], the following empirical relation between oxide ion polarizability and average electronegativity is as follows:

$$
\alpha_{\mathrm{O} 2-}(n)=4.624-0.7569 \zeta_{a v},
$$

where, $\zeta_{a v}$ is the average electronegativity of the material (or glass).

It is with great regret that this equation is not accurate to calculate electronegativity of a glass and so it needs some amendment. Accordingly a modified formula with a minor change in Equation (20) can be rewritten as the following:

$$
\alpha_{\mathrm{O} 2-}(n)=4.624-0.6430 \zeta_{a v}
$$

This new Equation (21) measures the values of electronegativity of silicate glasses under study which are in agreement with the values of electronegativity as measured by other researchers. We have also developed our own model known as Zahid model correlating oxide ion polarizability and electronegativity and that model now exists as

$$
0.92 \zeta_{a v}=6.039-\alpha_{\mathrm{O} 2-}(n)
$$


The values of electronegativity of silicate glasses as measured by Equation (21) are in good agreement with the values measured using Equation (22). All the values of electronegativity measured using Equations (21) and (22) are included in Tables 8-10, and are plotted in Figures 9-14.

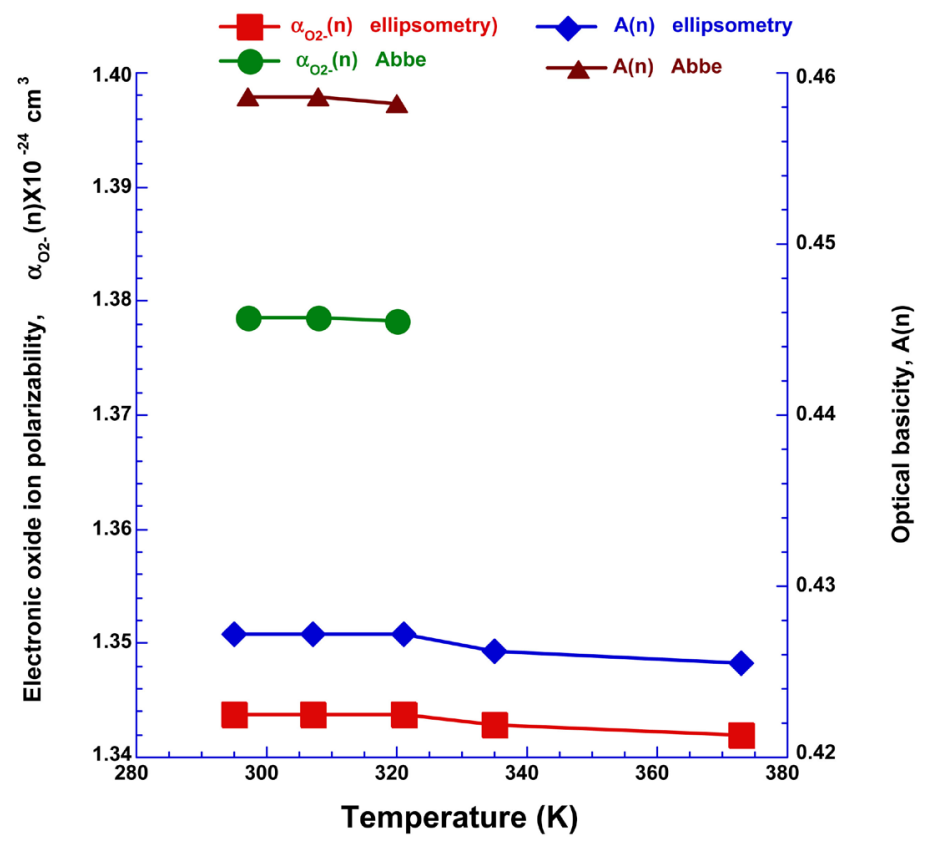

Figure 9. The plot of refractive index based electronic oxide ion polarizability and optical basicity of silica glass as a function of temperature using ellipsometry and Abbe refractometer.

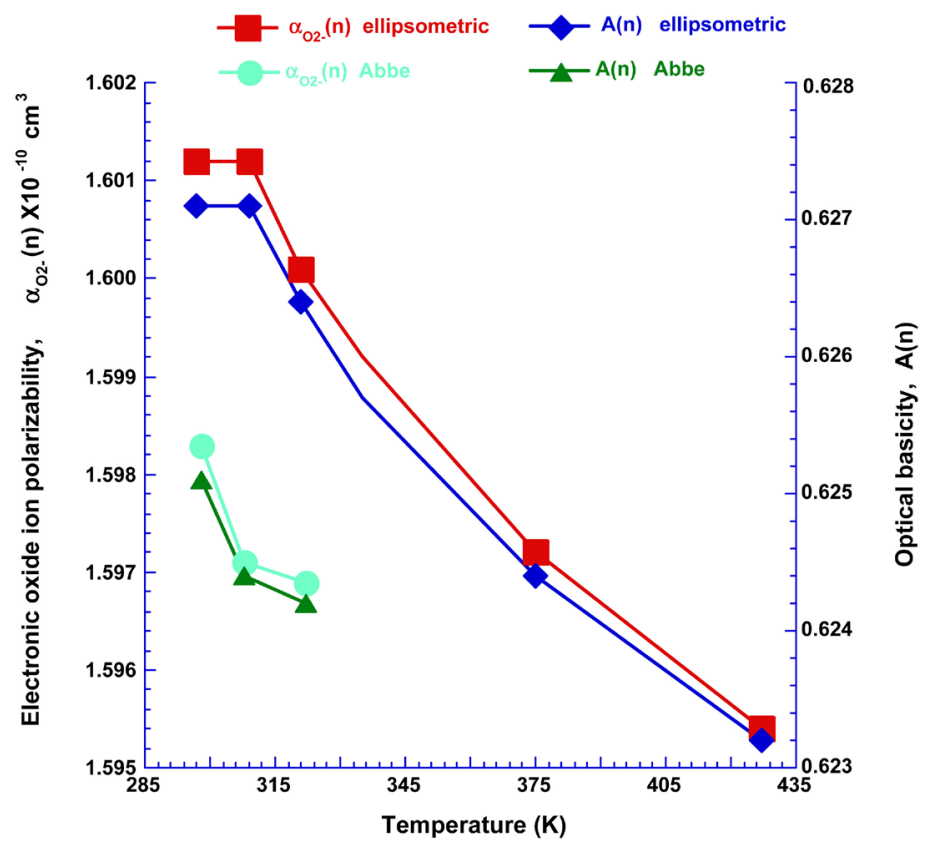

Figure 10. The plots of refractive index based electronic oxide ion polarizability and optical basicity of soda lime glass versus temperature using ellipsometry and Abbe refractometer. 


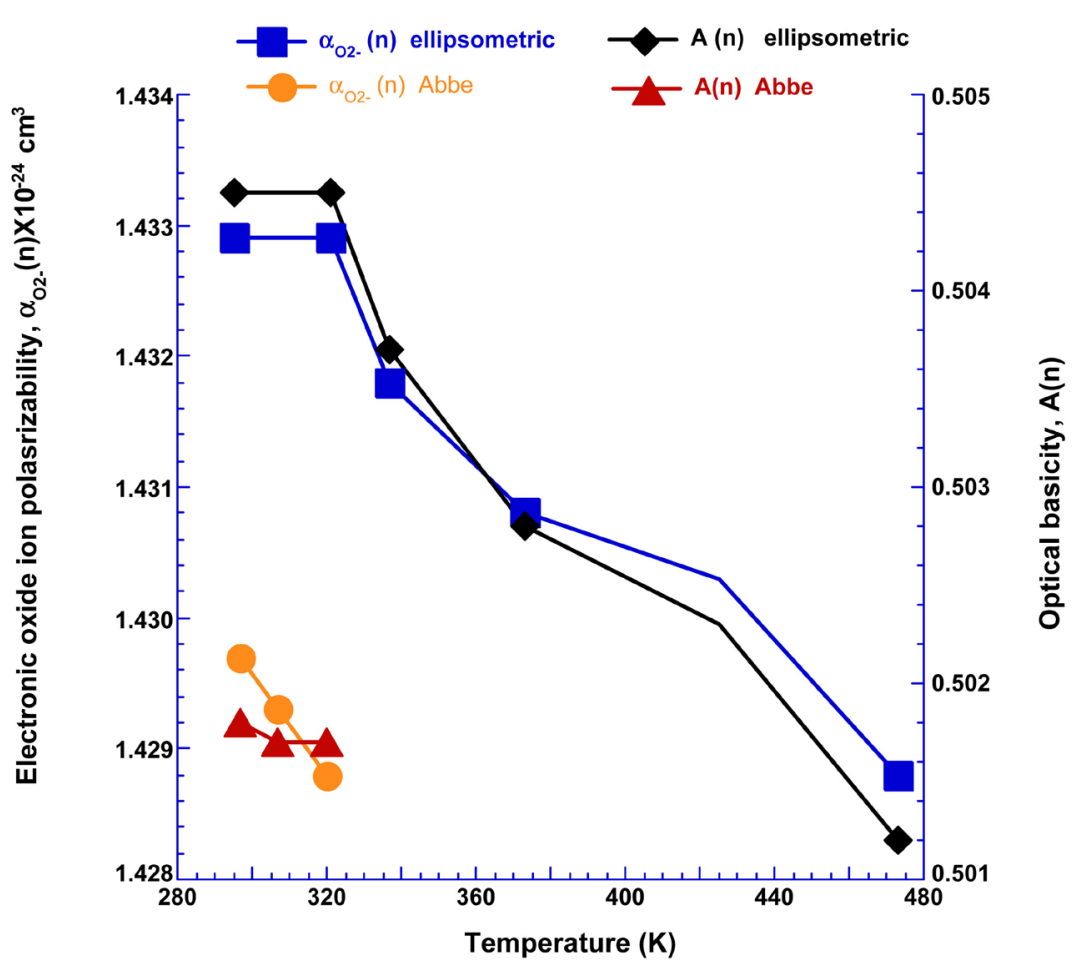

Figure 11. The plots of refractive index based electronic oxide ion polarizability, $\alpha_{\mathrm{O} 2-}(n)$ and optical basicity, $A(n)$ of 7059 glass using ellipsometry and Abbe refractometer.

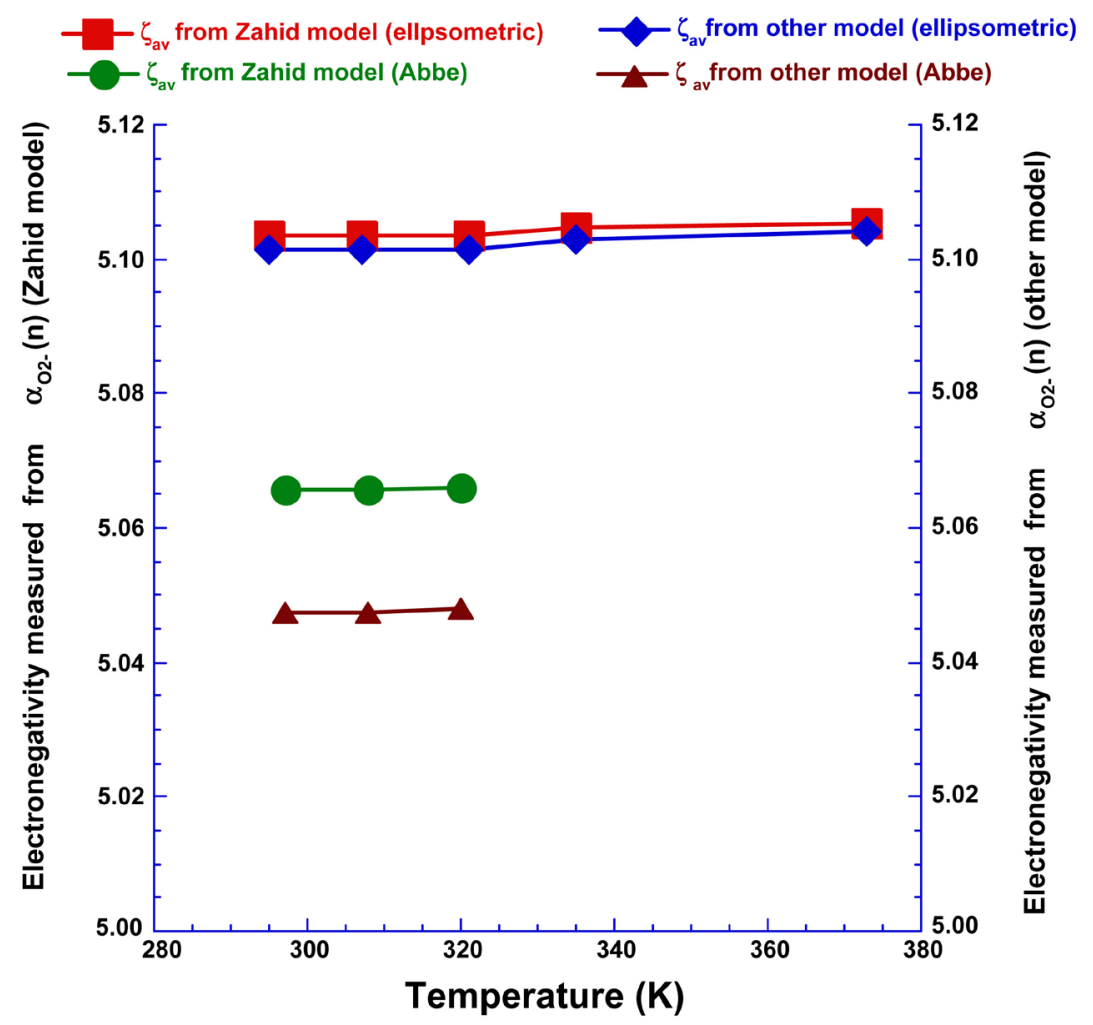

Figure 12. The plot of electronegativity of silica glass measured from oxide ion polarizability (Zahid and Reddy models) against temperature using ellipsometry and Abbe refractometer. 


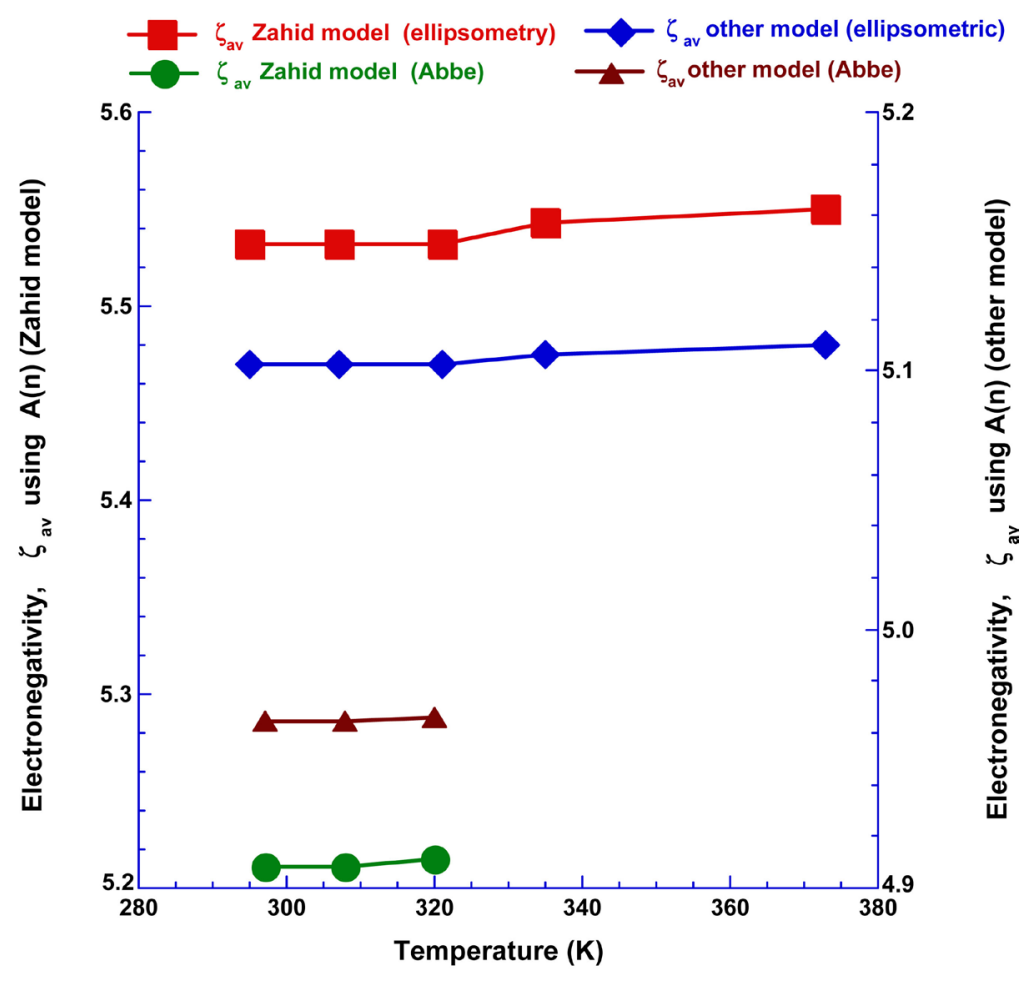

Figure 13. The plot of electronegativity of silica glass measured from optical basicity, $A$ (n) [Zahid and Reddy models] against temperature using ellipsometry and Abbe refractometer .

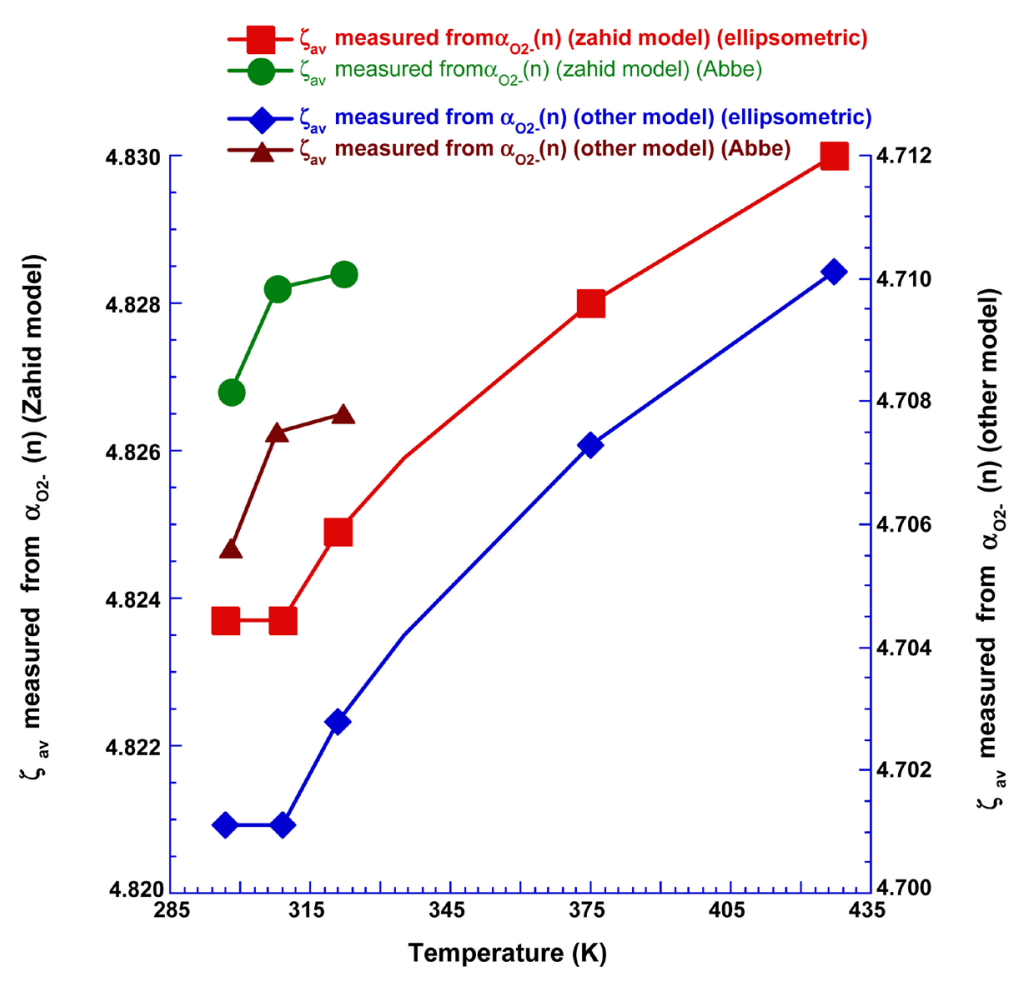

Figure 14. The changes in electronegativity of soda lime glass measured from oxide ion polarizability (Zahid and Reddy models) against temperature using ellipsometer and Abbe refractometer. 
Table 8. Temperature dependent data of silica glass regarding $n, A(n), \alpha_{\mathrm{O} 2-}(n), \zeta_{\mathrm{av}}\left(A_{n}\right)$, $\zeta_{a v}\left\{\alpha_{\mathrm{O} 2-}(n)\right\}$ [all the symbols are defined in the text] using ellipsometer and abbe refractometer.

\begin{tabular}{|c|c|c|c|c|c|c|c|}
\hline \multirow[b]{2}{*}{$\begin{array}{c}\text { Temperature } \\
\text { (K) }\end{array}$} & \multicolumn{7}{|c|}{ Ellipsometric } \\
\hline & $n$ & $\begin{array}{c}\alpha_{\mathrm{O} 2-}(n) \\
\left(\times 10^{-24}\right. \\
\left.\mathrm{cm}^{3}\right)\end{array}$ & $A(n)$ & $\begin{array}{c}\zeta_{a v}\left(A_{n}\right) \\
\text { Zahid } \\
\text { model }\end{array}$ & $\begin{array}{l}\zeta_{a v}\left(A_{n}\right) \\
\text { Reddy } \\
\text { model }\end{array}$ & $\begin{array}{c}\zeta_{a v}\left\{\alpha_{\mathrm{O} 2-}(n)\right\} \\
\text { Zahid } \\
\text { model }\end{array}$ & $\begin{array}{c}\zeta_{a v}\left\{\alpha_{\mathrm{O} 2-}(n)\right\} \\
\operatorname{Reddy} \\
\text { model }\end{array}$ \\
\hline 295.0 & 1.5119 & 1.3438 & 0.4272 & 5.5317 & 5.1022 & 5.1035 & 5.1014 \\
\hline 307.0 & 1.5119 & 1.3438 & 0.4272 & 5.5317 & 5.1022 & 5.1035 & 5.1014 \\
\hline 321.0 & 1.5119 & 1.3438 & 0.4272 & 5.5317 & 5.1022 & 5.1035 & 5.1014 \\
\hline 335.0 & 1.5115 & 1.3428 & 0.4262 & 5.5426 & 5.1066 & 5.1046 & 5.1030 \\
\hline \multirow[t]{2}{*}{373.0} & 1.5111 & 1.3420 & 0.4255 & 5.5504 & 5.1097 & 5.1054 & 5.1042 \\
\hline & \multicolumn{7}{|c|}{ Abbe } \\
\hline 297.0 & 1.5276 & 1.3786 & 0.4586 & 5.2111 & 4.9645 & 5.0657 & 5.0473 \\
\hline 308.0 & 1.5275 & 1.3786 & 0.4586 & 5.2111 & 4.9645 & 5.0657 & 5.0473 \\
\hline 322.0 & 1.5274 & 1.3782 & 0.4582 & 5.2149 & 4.9662 & 5.0661 & 5.0479 \\
\hline
\end{tabular}

Table 9. Temperature dependent data of soda lime glass regarding $n, A(n), \alpha_{\mathrm{O} 2-}(n), \zeta_{a v}$ $\left(A_{n}\right), \zeta_{a v}\left\{\alpha_{\mathrm{O} 2-}(n)\right\}$ [all the symbols are defined in the text] using ellipsometer and abbe refractometer.

\begin{tabular}{|c|c|c|c|c|c|c|c|}
\hline \multirow[b]{2}{*}{$\begin{array}{c}\text { Temperature } \\
\text { (K) }\end{array}$} & \multicolumn{7}{|c|}{ Ellipsometric } \\
\hline & $n$ & $\begin{array}{c}a_{\mathrm{O} 2-}(n) \\
\left(\times 10^{-24}\right. \\
\left.\mathrm{cm}^{3}\right)\end{array}$ & $A(n)$ & $\begin{array}{c}\zeta_{a v}\left(A_{n}\right) \\
\text { Zahid } \\
\text { model }\end{array}$ & $\begin{array}{l}\zeta_{a v}\left(A_{n}\right) \\
\text { Reddy } \\
\text { model }\end{array}$ & $\begin{array}{c}\zeta_{a v}\left\{a_{\mathrm{O} 2-}(n)\right\} \\
\text { Zahid } \\
\text { model }\end{array}$ & $\begin{array}{c}\zeta_{a V}\left\{\alpha_{\mathrm{O} 2-}(n)\right\} \\
\text { Reddy } \\
\text { model }\end{array}$ \\
\hline 297.0 & 1.5086 & 1.6012 & 0.6271 & 4.0393 & 4.2251 & 4.8237 & 4.7011 \\
\hline 309.0 & 1.5086 & 1.6012 & 0.6271 & 4.0393 & 4.2251 & 4.8237 & 4.7011 \\
\hline 321.0 & 1.5082 & 1.6001 & 0.6264 & 4.0429 & 4.2282 & 4.8249 & 4.7028 \\
\hline 335.0 & 1.5079 & 1.5992 & 0.6257 & 4.0469 & 4.2312 & 4.8259 & 4.7042 \\
\hline 375.0 & 1.5072 & 1.5972 & 0.6244 & 4.0531 & 4.2370 & 4.8280 & 4.7073 \\
\hline \multirow[t]{2}{*}{427.0} & 1.5065 & 1.5954 & 0.6232 & 4.0592 & 4.2422 & 4.8300 & 4.7101 \\
\hline & \multicolumn{7}{|c|}{ Abbe } \\
\hline 298.0 & 1.5074 & 1.5983 & 0.6251 & 4.0495 & 4.2339 & 4.8268 & 4.7056 \\
\hline 308.0 & 1.5072 & 1.5971 & 0.6244 & 4.0531 & 4.2370 & 4.8282 & 4.7075 \\
\hline 322.0 & 1.5070 & 1.5969 & 0.6242 & 4.0541 & 4.2378 & 4.8284 & 4.7078 \\
\hline
\end{tabular}

Table 10. Temperature dependent data of 7059 glass regarding $n, A(n), \alpha_{\mathrm{O} 2-}(n), \zeta_{a v}\left(A_{n}\right)$ and $\zeta_{\mathrm{av}}\left\{\alpha_{\mathrm{O} 2-}(n)\right\}$ [all the symbols are defined in the text] using ellipsometer and abbe refractometer.

\begin{tabular}{cccccccc}
\hline \multicolumn{8}{c}{ Ellipsometric } \\
\hline $\begin{array}{c}\text { Temperature } \\
(\mathrm{K})\end{array}$ & $\boldsymbol{n}$ & $\begin{array}{c}\boldsymbol{\alpha}_{\mathrm{O} 2-}(n) \\
\left(\times 10^{-24}\right. \\
\left.\mathrm{cm}^{3}\right)\end{array}$ & $A(n)$ & $\begin{array}{c}\zeta_{\text {av }}\left(A_{n}\right) \\
\text { Zahid } \\
\text { model }\end{array}$ & $\begin{array}{c}\zeta_{\text {av }}\left(A_{n}\right) \\
\text { Reddy } \\
\text { model }\end{array}$ & $\begin{array}{c}\zeta_{a v}\left\{\alpha_{\text {O2- }}(n)\right\} \\
\text { Zahid } \\
\text { model }\end{array}$ & $\begin{array}{c}\zeta_{a v}\left\{\alpha_{\text {O2- }}(n)\right\} \\
\text { Reddy } \\
\text { model }\end{array}$ \\
\hline 295.0 & 1.5296 & 1.4329 & 0.5045 & 4.8143 & 4.7631 & 5.0066 & 4.9628 \\
\hline
\end{tabular}


Continued

\begin{tabular}{llllllll}
\hline 309.0 & 1.5296 & 1.4329 & 0.5045 & 4.8143 & 4.7631 & 5.0066 & 4.9628 \\
321.0 & 1.5296 & 1.4329 & 0.5045 & 4.8143 & 4.7631 & 5.0066 & 4.9628 \\
337.0 & 1.5292 & 1.4318 & 0.5037 & 4.8206 & 4.7666 & 5.0078 & 4.9645 \\
373.0 & 1.5289 & 1.4308 & 0.5028 & 4.8277 & 4.7705 & 5.0089 & 4.9661 \\
425.0 & 1.5285 & 1.4303 & 0.5023 & 4.8317 & 4.7727 & 5.0095 & 4.9669 \\
473.0 & 1.5281 & 1.4288 & 0.5012 & 4.8404 & 4.7775 & 5.0111 & 4.9692 \\
\hline & & & \multicolumn{7}{c}{ Abbe } & & \\
\hline 297.0 & 1.5283 & 1.4297 & 0.5018 & 4.8357 & 4.7749 & 5.0101 & 4.9678 \\
307.0 & 1.5282 & 1.4293 & 0.5017 & 4.8364 & 4.7753 & 5.0105 & 4.9684 \\
322.0 & 1.5281 & 1.4288 & 0.5017 & 4.8420 & 4.7784 & 5.0111 & 4.9692 \\
\hline
\end{tabular}

Similarly, in the case of optical basicity and electronegativity, we have only followed the model by Reddy [76] [77] who have derived the following empirical relationship for the refractive index based optical basicity, $A(n)$ associated with the electronegativity of a material:

$$
A(n)=1.59-0.2279 \zeta_{1 a v},
$$

where $\zeta_{1 a v}$ is the average electronegativity of the material. This formulation is very suitable for the silicate glasses. Here, we have also established the empirical relation between optical basicity and average electronegativity known as Zahid model and that exists as:

$$
\frac{2}{A(n)}=\zeta_{a v}-0.85
$$

The values of electronegativity using Zahid model [Equation (24)] are also in good agreement with the values measured using other models [Equation (23)]. All the values of electronegativity measured using Equation (23) and Equation (24) are tabulated in Tables 8-10, and are plotted in Figures 9-17.

Figures 9-17 show that for a silica glass, both the refractive index based optical basicity.

$a_{\mathrm{O} 2-}(n)$ and $A(n)$ are decreased from 1.3438 to 1.3420 and from 0.4272 to 0.4255 , respectively; while the values of $\left(\zeta_{1 a r}\right)$ calculated) using Zahid model and other models on the base of $\alpha_{\mathrm{O} 2-}(n)$ are increased from 5.1035 to 5.1054 and from 5.1014 to 5.1042, respectively; and are increased from 5.5317 to 5.5504 and from 5.1022 to 5.1097 on the base of $A(n)$, respectively over the temperature range 295 - $373 \mathrm{~K}$ using ellipsometer. Both the refractive index based optical basicity $\alpha_{02-}(n)$ and $A(n)$ relating to silica glass are decreased from 1.3786 to 1.3782 and from 0.4586 to 0.4582 , respectively; while the values of $\left(\zeta_{1 a r}\right)$ calculated) using Zahid model and other models on the base of $\alpha_{\mathrm{O} 2-}(n)$ are increased from 5.0657 to 5.0661 and from 5.0473 to 5.0479 , respectively; and are increased from 5.2111 to 5.2149 and from 4.9645 to 4.9662 on the base of $A(n)$, respectively over the temperature range 297 - $322 \mathrm{~K}$ using Abbe refractometer. 


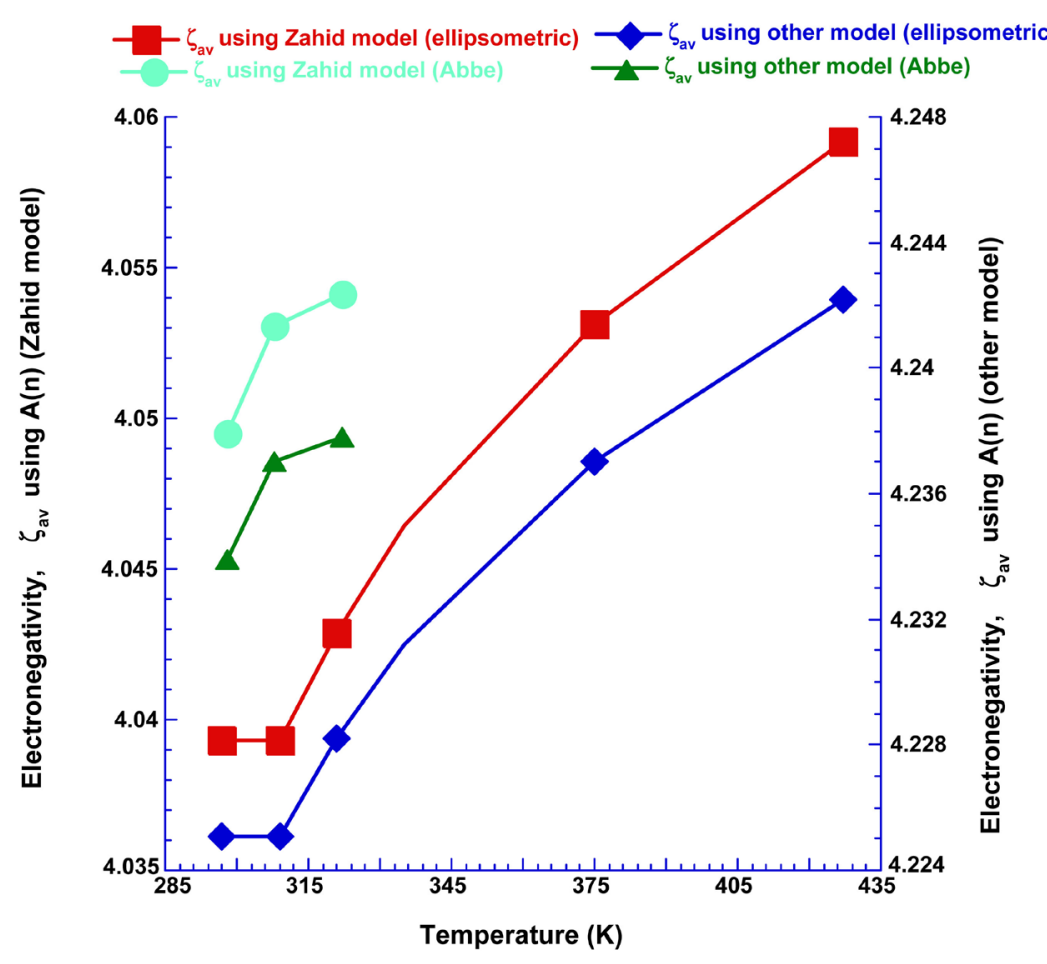

Figure 15. The changes in electronegativity of soda lime glass measured from optical basicity, $A(n)$ [Zahid and Reddy models] against temperature using ellipsometry and Abbe refractometer.

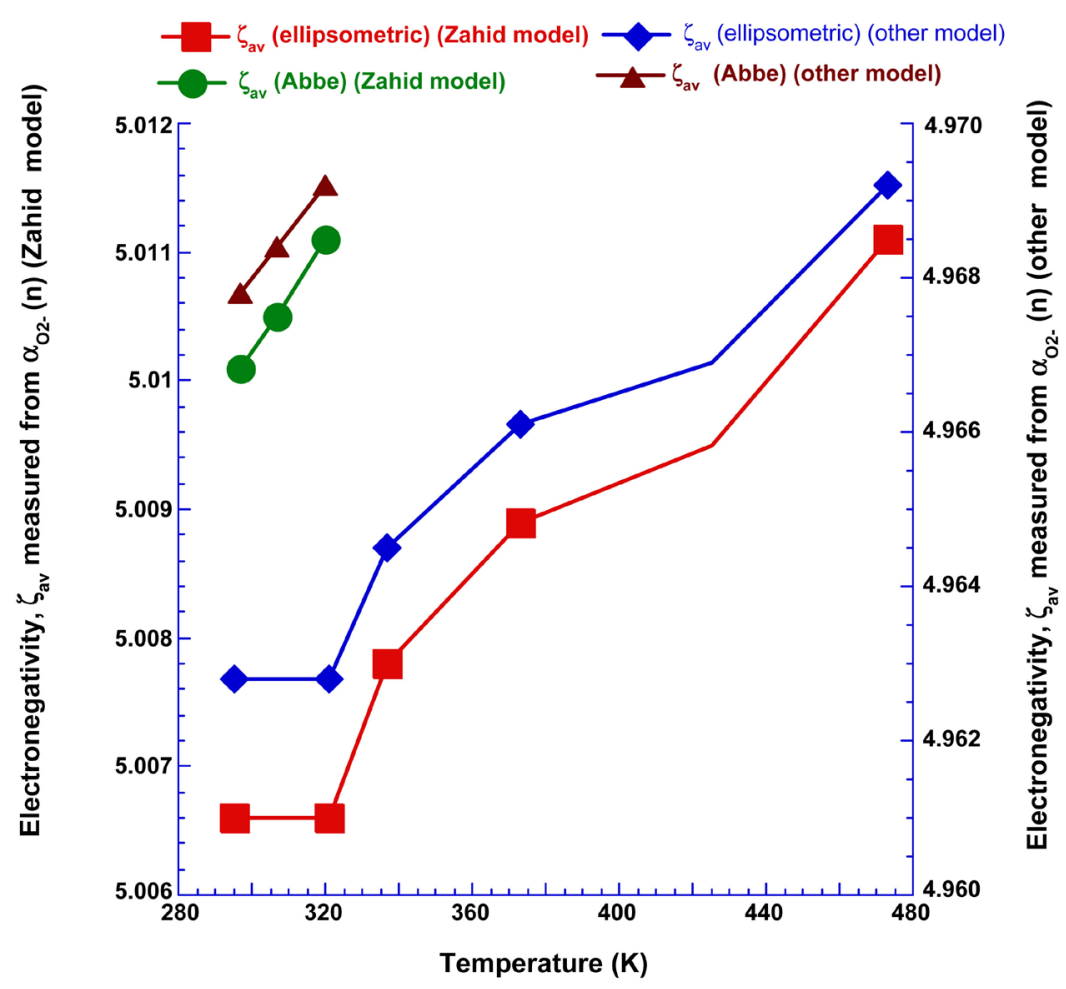

Figure 16. The plots of electronegativity of 7059 glass measured from oxide ion polarizability \{Zahid and Reddy models\} versus temperature using ellipsometry and Abbe refractometer. 


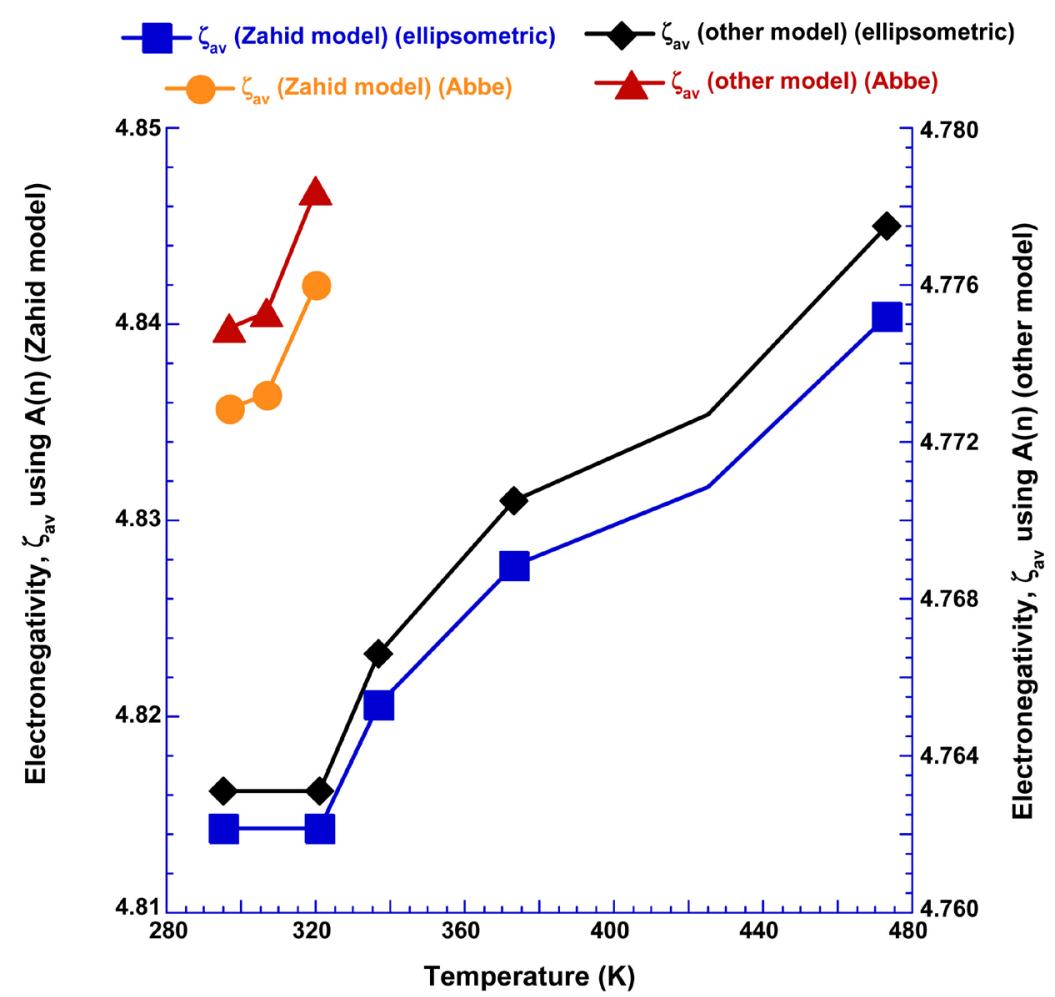

Figure 17. The plots of electronegativity of 7059 glass measured from optical basicity, $A$ (n) \{Zahid and Reddy models\} versus temperature using ellipsometry and Abbe refractometer.

The values of $\alpha_{\mathrm{O} 2-}$ ( $\left.n\right)$ and $A(n)$ relating to soda lime glass are decreased from 1.6012 to 1.5954 and from 0.6271 to 0.6232 , respectively, while the calculated values of $\left(\zeta_{\text {lav }}\right)$ using Zahid model and other models on the base of $\alpha_{\mathrm{O} 2-}(n)$ are increased from 4.8237 to 4.830 and from 4.7011 to 4.7101 , respectively; and are increased from 4.0393 to 4.0592 and from 4.2251 to 4.2422 on the base of $A(n)$, respectively over the temperature range 297 - $427 \mathrm{~K}$ using ellipsometer. Both the refractive index based optical basicity $\alpha_{\mathrm{O} 2-}(n)$ and $A(n)$ relating to soda lime glass are decreased from 1.3786 to 1.3782 and from 0.4586 to 0.4582 , respectively; while the calculated values of $\left(\zeta_{1 a r}\right)$ using Zahid model and Reddy model on the base of $\alpha_{\mathrm{O} 2-}(n)$ are increased from 5.0657 to 5.0661 and from 5.0473 to 5.0479 , respectively; and are increased from 5.2111 to 5.2149 and from 4.9645 to 4.9662 on the base of $A(n)$, respectively over the temperature range $297-322 \mathrm{~K}$ using Abbe refractometer.

In the case of borosilicate 7059 glass, both $\alpha_{02-}(n)$ and $A(n)$ are decreased from 1.4329 to 1.4288 and from 0.5045 to 0.5012 , respectively; while the values of electronegativity $\left(\zeta_{1 \mathrm{ar}}\right)$ calculated on the base of $\alpha_{\mathrm{O2}-}(n)$ using Zahid model and other models, are increased from 5.0066 to 5.0111 and from 4.9628 to 4.9692 , respectively; and are increased from 4.8143 to 4.8404 and from 4.7631 to 4.7775, respectively, measured on the base of $A(n)$ over the temperature range 295 - $473 \mathrm{~K}$ using ellipsometer. Both the refractive index based optical basicity $\alpha_{\mathrm{O} 2-}(n)$ and $A(n)$ relating to borosilicate 7059 glass are decreased from 1.4297 to 
1.4288 and from 0.5018 to 0.5017 , respectively; while the calculated values of $\left(\zeta_{1 a r}\right)$ using Zahid model and Reddy model on the base of $\alpha_{02-}(n)$, are increased from 5.0101 to 5.0111 and from 4.9678 to 4.9692 , respectively, and are increased from 4.8357 to 4.8420 and from 4.7749 to 4.7784 on the base of $A(n)$, respectively over the temperature range 297 - $322 \mathrm{~K}$ using Abbe refractometer.

Generally, as the difference in electronegativity between any two elements within a chemical compound approaches zero, the bond becomes less ionic and more covalent. As a difference of electronegativity exceeds zero and approaches 1.7, the bond becomes more polar covalent, and if the difference gets increasingly larger than 1.7 , a bond between any two elements is more likely to be ionic [80] [81].

Since the calculated values of electronegativity are found in the range 4.0393 - 5.5504 for the silicate glasses (silica, soda lime, and borosilicate 7059), so from the above analysis all these glasses have an ionic character.

\section{Summary and Conclusions}

We have used two optical techniques: ellipsometry at a wavelength, $\lambda$ of 632.8 $\mathrm{nm}$ and Abbe's refractometer at $\lambda$ of $589.3 \mathrm{~nm}$, to measure the optical and physical properties of silicate glasses over the temperature range from 295 to $473 \mathrm{~K}$.

The values of refractive index $(n)$ for silica, soda lime and borosilicate 7059 glasses are decreased but the optical band gap $\left(E_{g}\right)$ values are increased over the temperature range 295 - $473 \mathrm{~K}$ using ellipsometer and Abbe refractometer. The values of oxide ion polarizability $\left[\alpha_{02-}(n)\right.$ and $\left.\alpha_{02-}\left(E_{g}\right)\right]$ regarding silicate glasses have got the decreasing trend over the temperature range 295 - $373 \mathrm{~K}$ using ellipsometer or Abbe refractometer. The differences between the values of $\alpha_{02-}\left(E_{g}\right)$ and $\alpha_{\mathrm{O} 2-}(n)$ can be explained by the existence of the localized density states in band gap energy based on the theory of conduction of non-crystalline.

We have also measured refractive index and optical band gap based optical basicity $\left[A(n)\right.$ and $\left.A\left(E_{g}\right)\right]$ relating to silicate glasses. Experimental results show that $A(n)$ and $A\left(E_{g}\right)$ of silica glasses are decreased over the temperature range 295 - $373 \mathrm{~K}$ using ellipsometer or Abbe refractometer. Further, we have found that for silicate glasses, the values of electronegativity $\left(\zeta_{1 a v}\right)$ measured using $\mathrm{Za}$ hid model and Reddy model on the base of $\alpha_{02-}$ ( $n$ ) or on the base of $A(n)$ are increased over the temperature range $295-373 \mathrm{~K}$ using both the optical instruments.

From these findings, we conclude that the optical band gap $\left(E_{g}\right)$ values of silicate glasses increase as temperature increases. Such an increase can be explained by suggesting that the non-bridging oxygen (NBO) ions content is decreased due to an increase in the value of $E_{g}$. It is also very clear that both oxide ion polarizability and optical basicity have the same decreasing trend as the temperature is increased. This trend occurs due to the decreasing amount of non-bridging oxygen (NBO), and that happens due to small single bond strength and a little change in the electronic polarizability associated with the si- 
licate glass system. Next, the calculated values of electronegativity are found to be in the range $4.0393-5.5504$ for the reported silicate glasses. And from this result we conclude that all these glasses have an ionic character.

Also, the decreasing trend in both optical basicity and of oxide ion polarizability values suggest that the silicate glasses are not novel glasses (optical functional glasses) for non-linear optical (NLO) devices or for three dimensional displays and for biological systems.

\section{Acknowledgements}

This research was done in the EEE department at Imperial College London by private fundings. The author would like to acknowledge the invaluable assistance provided by the technicians of the EEE laboratories.

\section{Funding Information}

Sampling and experimental process were financially supported by the author.

\section{Ethics}

This article is original and contains unpublished material. Author declares that there is no ethical issue and no conflict of interest that may arise after the publication of this manuscript.

\section{Conflicts of Interest}

The author declares no conflicts of interest regarding the publication of this paper.

\section{References}

[1] Baino, F., Fiorilli, S. and Brovarone, C.V. (2017) Composite Biomaterials Based on Sol-Gel Mesoporous Silicate Glasses: A Review. Journal of Biomedical Engineering, 4, 15-32. https://doi.org/10.3390/bioengineering4010015

[2] Rahaman, M.N., Day, D.E., Bal, B.S., Fu, Q., Jury, S.B., Bonewald, L.F. and Tomsia, A.P. (2011) Bioactive Glass in Tissue Engineering. Acta Biomaterialia, 7, 2355-2373. https://doi.org/10.1016/j.actbio.2011.03.016

[3] Joseph, C.M., Binu, P.R. and Shreekrisnakumar, K. (2001) Preparation and Physical Properties of CuPc-Substituted Borate Glass. Materials Letters, 50, 251-253. https://doi.org/10.1016/S0167-577X(01)00234-8

[4] Chimalawong, P., Kirdsiri, K. and Kaewkhao, J. (2012) Investigation on the Physical and Optical Properties of $\mathrm{Dy}^{3+}$ Doped Soda-Lime-Silicate Glasses. Procedia, 32, 690-698. https://doi.org/10.1016/j.proeng.2012.01.1328

[5] Lousteau, J., Boetti, N.G., Negro, D., Mura, E., Scarpignato, G.C., Perrone, G., Milanese, D. and Abrate, S. (2017) Photonic Glasses for IR and Mid-IR Spectral Range. Proceedings SPIE, 10564, Article ID: 1056435.

[6] Regi, M. and Balas, F. (2008) Silica Materials for Medical Applications. Open Biomedical Engineering Journal, 2, 1-9. https://doi.org/10.2174/1874120700802010001

[7] Boyd, D.C., Danielson, P.S., Thompsom, D.A., Velez, M., Reis, S.T. and Brow, R.K. 
(2005) Glass. In: Kirk-Othmer, Encyclopedia of Chemical Technology, 5th Edition, Willey, Hoboken, 565-626. https://doi.org/10.1002/0471238961.0712011902152504.a01.pub2

[8] Donald, I. (2001) Novel Glasses and Their Applications. Discovery, 2, 2-9.

[9] Donald, I. (1984) Methods for Improving the Mechanical Properties of Oxide Glasses. Journal of Materials Science, 24, 4177-4208. https://doi.org/10.1007/BF00544488

[10] Sebastian, M.T. and Jantunen, H. (2008) Low Loss Dielectric Materials for LTCC Applications: A Review. International Material Review, 53, 57-90. https://doi.org/10.1179/174328008X277524

[11] Leiser, C. (1962) Importance of Lead in Glass-Part One. The Glass Industry, 44, 509-513.

[12] Jacq, C., Maeder, T. and Ryser, P. (2009) Sensors and Packages Based on LTCC and Thick-Film Technology for Severe Conditions. Sadhana, 34, 677-687.

https://doi.org/10.1007/s12046-009-0031-Z

[13] Jacq, C., Maeder, T. and Ryser, P. (2004) High-Strain Response of Piezoresistive Thick-Film Resistors on Titanium Alloy Substrates. Journal of the European Ceramic Society, 24, 1897-1900. https://doi.org/10.1016/S0955-2219(03)00467-9

[14] Cheek, G.C., Mertens, R.P., Overstraeten, R.V. and Frisson, L. (1984) Thick-Film Metallization for Solar Cell Applications. IEEE Transactions on Electron Devices, 31, 602-605. https://doi.org/10.1109/T-ED.1984.21575

[15] Schubert, G., Huster, F. and Fath, P. (2006) Physical Understanding of Printed Thick-Film Film Front Contact of Crystalline Si Solar Cells: Review of Existing Models and Recent Developments. Solar Energy Materials \& Solar Cells, 90, 3399-3406. https://doi.org/10.1016/j.solmat.2006.03.040

[16] Wang, Z., Huang, F., Yang, Q., Hua, Y., Zhang, J., Ye, R. and Xu, S. (2019) Efficient Controllable NIR-MIR Luminescence Conversion in Optical Nanostructured Silicate Glasses. The Journal of Physical Chemistry C, 123, 14662-14668. https://doi.org/10.1021/acs.jpcc.9b02943

[17] Baki, M.A. and Diasty, F.E. (2013) Glasses for Photonic Technologies. International Journal of Optics an Applications, 3, 125-137.

[18] Mysen, B.O. and Virgo, D. (1994) Structure and Properties of Silicate Glasses and Melts: Theories and Experiment. In: Marfunin, A.S., Ed., Advanced Mineralogy, Springer, Berlin, 238-254. https://doi.org/10.1007/978-3-642-78523-8 14

[19] Hasan, M.S., Zwanziger, U.W. and Boyd, D. (2015) Composition-Structure-Properties Relationship of Strontium Borate Glasses for Medical Applications. Journal of Biomedical Materials Research Part A, 103, 2344-2354.

https://doi.org/10.1002/jbm.a.35361

[20] Regi, M.V. and Balas, F. (2008) Silica Materials for Medical Applications. Journal of Open Biomedical Engineering, 2, 1-9. https://doi.org/10.2174/1874120700802010001

[21] Volf, M.B. (1990) Glass Science and Technology. Vol. 10. Technical Approach to Glass. Elsevier, Amsterdam.

[22] Kurkjian, C.R. and Prindle, W.R. (1998) Perspectives on the History of Glass Composition. Journal of the American Ceramic Society, 81, 795-813. https://doi.org/10.1111/j.1151-2916.1998.tb02415.x

[23] Sestak, J. and Foller, B. (2012) Some Aspects of Composition: Inorganic Polysialates. Journal of Thermal Analysis and Calorimetry, 108, 511-517. 
https://doi.org/10.1007/s10973-011-2037-0

[24] Wbyodarczyk, K.L., D, P.H. and Valer, M.M.M. (2019) Maskless, Rapid Manufacturing of Glass Microfluidic Devices Using a Picosecond Pulsed Laser. Scientific Reports, 9, Article No. 20215. https://doi.org/10.1038/s41598-019-56711-5

[25] Pranzo, D., Larizza, P., Filippini, D. and Percoco, G. (2018) Extrusion-Based 3D Printing of Microfluidic Devices for Chemical and Biomedical Applications: A Topical Review. Micromachines-Basel, 9, 374. https://doi.org/10.3390/mi9080374

[26] Khor, S.F., Talib, Z.A., Sidek, H.A.A., Daud, W.M. and Ng, B.H. (2009) Effects of $\mathrm{ZnO}$ on Dielectric Properties and Electrical Conductivity of Ternary Zinc Magnesium Phosphate Glasses. American Journal of Applied Sciences, 6, 1010-1014. https://doi.org/10.3844/ajassp.2009.1010.1014

[27] Vorshneya, A.K. (1994) Fundamentals of Inorganic Glasses. Academic Press, Boston, 570. https://doi.org/10.1016/B978-0-08-057150-8.50025-2

[28] Farhan, S.H. (2017) Study of Some Physical and Optical Properties of $\mathrm{Bi}_{2} \mathrm{O}_{3}$ $\mathrm{TeO}_{2} \mathrm{~V}_{2} \mathrm{O}_{5}$ Glasses. Australian Journal of Applied Science, 11, 171-178.

[29] Cupta, N., Kaur, A., Khanna, A., Gonzalez, F., Resquera, C., Iordanovo, R. and Chen, B. (2017) Structure Property Correlation in $\mathrm{TiO}_{2} \mathrm{Bi}_{2} \mathrm{O}_{3} \mathrm{~B}_{2} \mathrm{O}_{3} \mathrm{TeO}_{2}$ Glasses. Journal of Non-Crystalline Solids, 470, 168-177.

[30] Mallawany, E.R.R. (2002) Tellurite Glasses Handbook: Physical Properties and Data. CRC Press, Baca Raton, 540.

[31] Kuma, V.R. and Veeraiah, N. (1987) Infrared Spectral Investigations on $\mathrm{ZnF}_{2}-\mathrm{P}_{60}-\mathrm{TeO}_{2}$ Glasses. Journal of Materials Science Letters, 16, 1816-1818.

[32] Jackson, J., Smith, C., Massera, J., Rivew, C., Bungay, C., Petit, L., Richardson, K. (2009) Estimation of Peak Raman Gain Coefficient for $\mathrm{BaOBi}_{2} \mathrm{O}_{3} \mathrm{TeO}_{2}$ Glasses. Optical Express, 17, 9071-9079. https://doi.org/10.1364/OE.17.009071

[33] Tang, W., Mi and Shu, C.J. (2010) Viscosity and Thermal Expansion of Rare Earth Containing Soda-Lime-Silicate Glass. Journal of Alloys and Compounds, 504, 273-276. https://doi.org/10.1016/j.jallcom.2010.05.111

[34] Buczynski, R., Pysz, D., Kujawa, I., Fita, I.P., Pawlowska, M., Nowasielski, J., Radzeiwicz, C. and Stepien, R. (2007) Silicate All-Solid Photonic Crystal Fibers with a Glass High Index Contrast. SPIE 2007, Vol. 6588, Article ID: 658802. https://doi.org/10.1117/12.723454

[35] Li, W., Wang, L., Liu, X., Chen, D., Zhou, Q. and Hu, L. (2015) Silicate Glass All-Solid Photonic Band Gap Crystal Fiber. IEEE Photonics Technology Letters, 27, 189-192. https://doi.org/10.1109/LPT.2014.2364624

[36] Brunello, G., Elsayed, H. and Biosetto, L. (2019) Bioactive Glass and Silicate-Based Ceramic Coatings on Metallic Implants: Open Challenge or Outdated Topic. Materials (Basel), 12, 2929. https://doi.org/10.3390/ma12182929

[37] Buriahi, M.S.A., Sriwunkum, C., Arslan, H., Tonguc, B.T. and Bourham, M.A. (2020) Investigation of Barium Borate Glasses for Radiation Shielding Applications. Applied Physics A, 126, Article No. 68. https://doi.org/10.1007/s00339-019-3254-9

[38] Pedone, A., Malavasi, G., Cormack, A.N., Segre, U. and Menzziani, M.C. (2007) Insight into Elastic Properties of Binary Alkali Silicate Glasses. Prediction and Interpretation through Atomistic Simulation Techniques. Chemical Materials, 19, 3144-3154. https://doi.org/10.1021/cm062619r

[39] Buratti, C., Moretti, E. and Zinzi, M. (2017) High Energy-Efficient Windows with Silica Aerogel for Building Refurbishment: Experimental Characterization and Preliminary Simulations in Different Climate Conditions. Buildings, 7, 8. 
https://doi.org/10.3390/buildings7010008

[40] Jelli, B.P., Hynd, A., Gustavsen, A., Arasteh, D., Goudey, H. and Hart, R. (2012) Fenestration of Today and Tomorrow: A State of the Art Review and Future Research Opportunities. Solar Energy Materials \& Solar Cells, 96, 1-28.

https://doi.org/10.1016/j.solmat.2011.08.010

[41] Forsber, C.W. and Beahm, E.C. (1998) Recovery of Fissile Materials from Wastes and Conversion of the Residual Waste to Glass. Nuclear Technology, 123, 341-349. https://doi.org/10.13182/NT98-A2904

[42] Mishra, R.K., Kumar, S., Tomar, B.S., Tyagi, A.K., Kaushik, C.P., Raj, K. and Manchanda, V.K. (2008) Effect of Barium on Diffusion of Sodium in Borosilicate Glass. Journal of Hazardous Materials, 156, 129-134. https://doi.org/10.1016/j.jhazmat.2007.12.006

[43] Malow, G. and Lutze, W. (1975) Sodium Diffusion in Borosilicate Glasses. Part 1 Influence of Glass Composition. Physical Chemical Glasses, 16, 113-116.

[44] Wang, J., Reekie, L., Brocklesby, W.S., Chow, Y.T. and Payne, D.N. (1995) Fabrication, Spectroscopy and Laser Performance of $\mathrm{Nd}^{3+}$-Doped Lead-Silicate Glass Fibers. Journal of Non-Crystalline Solids, 180, 207-216. https://doi.org/10.1016/0022-3093(94)00474-9

[45] Szpikowska, B.S., Pawlik, N., Govyezka, T. and Pisarski, W.A. (2015) Influence of Silicate Sol Gel Host Matrices and Catalyst Agents on the Luminescent Properties of $\mathrm{Eu}^{3+} / \mathrm{Gd}^{3+}$ under Different Excitation. RSC Advanced, 5, 98773-98782.

https://doi.org/10.1039/C5RA15562B

[46] Dragic, P.G., Cavillon, M. and Ballato, J. (2018) Materials for Optical Fiber Lasers: A Review. Applied Physics Reviews, 5, Article ID: 041301. https://doi.org/10.1063/1.5048410

[47] Richardson, D.J., Nilsson, J. and Clarkson, W.A. (2012) High Power Fibre Lasers Current Status and Future Perspectives. Journal of Optical Society America B, 27, 63-92. https://doi.org/10.1364/JOSAB.27.000B63

[48] Ji, C., Zhang, Z., Masuda, T., Kudo, Y. and Guo, L.J. (2019) Vivid-Coloured Silicon Solar Panels with High Efficiency and Non-Iridescent Appearance. Nanoscale Horizons, 4, 874-880. https://doi.org/10.1039/C8NH00368H

[49] Efimov, O.M., Galel, K., Garnov, S.V., Glebov, L.B., Grantham, S., Richardson, M. and Soileau, M.J. (1998) Colour-Centre Generation in Silicate Exposed to Infrared Femtosecond Pulses. Journal of the Optical Society of America B, 15, 193-199. https://doi.org/10.1364/JOSAB.15.000193

[50] Keiser, G.E. (2000) Optical Fiber Communications. 3rd Edition. International Editions: Electrical Engineering Series. McGraw-Hill Higher Education, New York.

[51] Vasilev, V.Y. (2005) Borophosphosilicate Glass Films in Silicon Microelectronics, Part 2: Structure and Applications. Russian Microelectronics, 34, 67-77.

https://doi.org/10.1007/s11180-005-0020-9

[52] Suresh, B., Purnach, N., Zhydachevskii, Y.A., Brik, M.G., Reddy, M.S., Suchocki, A., Piasecki, M. and Veeraiah, N. (2017) Influence of $\mathrm{Bi}^{3+}$ Ions on the Amplification of $1.3 \mu \mathrm{m}$ Emission of $\operatorname{Pr}^{3+}$ Ions in Lead Silicate Glasses for the Applications in Second Telecom Windows Communication. Journal of Luminescence, 182, 312-322. https://doi.org/10.1016/j.jlumin.2016.10.036

[53] Azzam, R.M.A. and Bashara, N.M. (1989) Ellipsometry and Polarized Light. Journal Optical Society America A, 6, 1513-1521. https://doi.org/10.1364/JOSAA.6.001513

[54] Hilfiker, J.N., Stadermann, M., Sun, J., Tiwald, T., Hale, J.S., Miller, P.E. and Rud- 
dle, C.A. (2017) Determining Thickness and Refractive Index from Free Standing Ultra-Thin Polymer Films with Spectroscopic Ellipsometry. Applied Surface Science, 421, 508-512. https://doi.org/10.1016/j.apsusc.2016.08.131

[55] Hussain, Z. (1999) Vacuum Temperature-Dependent Ellipsometric Studies on $\mathrm{WO}_{3}$ Thin Films. Applied Optics, 38, 7112-7127. https://doi.org/10.1364/AO.38.007112

[56] McCrackin, F.L. (1969) NBS Technical Note 479. U.S. Government Printing Office, Washington DC.

[57] Hussain, Z. (2018) Optical Constants and Electrochromic Characteristics of $\mathrm{M}_{\mathrm{x}} \mathrm{WO}_{3}$ Bronzes. Applied Optics, 57, 5720-5732. https://doi.org/10.1364/AO.57.005720

[58] Azlan, M.N., Halimah, M.K., Shafinas, S.Z. and Daud, W.M. (2015) Electronic Polarizability of Zinc Borotellurite Glass System Containing Erbium Nanoparticles. Material Express, 4, 211-218. https://doi.org/10.1166/mex.2015.1236

[59] Haralampieva, A., Lozanova, I.S. and Dimitrov, V. (2012) Optical Properties and Structure of $\mathrm{BaO}-\mathrm{V}_{2} \mathrm{O}_{5}$ and $\mathrm{Fe}_{2} \mathrm{O}_{3}-\mathrm{BaO}-\mathrm{V}_{2} \mathrm{O}_{5}$ Glasses. Journal of Chemical Technology and Metallurgy, 47, 392.

[60] Bhatia, B., Meena, S.L., Parihar, V. and Poonia, M. (2015) Optical Basicity and Polarizability of $\mathrm{Nd}^{3+}$-Doped Bismuth Borate Glasses. New Journal of Glass and Ceramics, 5, 44-52. https://doi.org/10.4236/njgc.2015.53006

[61] Berwal, N.S., Dhankhar, S.P., Sharma, P., Kundu, R.S., Punja, R. and Kishore, N. (2017) Physical, Structural and Optical Characterization of Silicate Modified Bismuth-Borate-Tellurite Glasses. Journal of Molecular Structure, 1127, 636-644. https://doi.org/10.1016/j.molstruc.2016.08.033

[62] Dimitrov, V. and Sakka, S. (1996) Electronic Oxide Polarizability and Optical Basicity of Simple Oxides. International Journal of Applied Physics, 79, 1736-1740. https://doi.org/10.1063/1.360962

[63] Meena, S.L. and Bhatia, B. (2016) Polarizability and Optical Basicity of $\mathrm{Er}^{3+}$ Ions Doped Zinc Lithium Bismuth Borate Glasses. Journal of Pure Applied and Industrial Physics, 6, 175-183. https://doi.org/10.9790/4861-0804044954

[64] Dimitov, V. and Komatsu, T. (2002) Classification of Simple Oxides: A Polarizability Approach. Journal of Solid State Chemistry, 163, 100-112.

https://doi.org/10.1006/jssc.2001.9378

[65] Duffy, J.A. (1989) Electronic Polarizability and Related Properties of the Oxide Ion. Physics and Chemistry of Glasses, 30, 1-4.

[66] Honma, T., Benino, Y., Komatsu, T., Sato, R. and Dimitrov, R. (2002) Correlation among Electronic Polarizability, Optical Basicity, Interaction Parameter and XPS Spectra of $\mathrm{Bi}_{2} \mathrm{O}_{3}-\mathrm{B}_{2} \mathrm{O}_{3}$ Glasses. Physics and Chemistry of Glasses, 43, 32-40.

[67] Dimitov, V. and Komatsu, T. (2010) An Interpretation of Optical Properties of Oxides and Oxide Glasses in Terms of the Electronic ion Polarizability and Average Single Bond Strength. Journal University of Chemical Technology and Metallurgy, 45, 219-250.

[68] Tashera, T. and Dimitrov, V. (2015) Optical Properties and Structure of $\mathrm{B}_{2} \mathrm{O}_{3} \mathrm{BaO}$ $\mathrm{V}_{2} \mathrm{O}_{5}$ Glasses. Journal of Chemical Technology and Metallurgy, 50, 441-448.

[69] Malchukova, E., Boizot, B., Ghaleb, D. and Petite, G. (2005) Optical Properties of Pristine and $\gamma$-Irradiated Sm Doped Borosilicate Glasses. Nuclear Instruments and Methods in Physics Research Section A: Accelerators, Spectrometers, Detectors and Associated Equipment, 537, 411-414. https://doi.org/10.1016/j.nima.2004.08.054

[70] Vetrane, F., Boyer, J.C., Capobianco, J.A., Sepghini, A. and Bettinelli, M. (2002) 980 $\mathrm{nm}$ Excited Upconversion in an Er-Doped $\mathrm{ZnO}-\mathrm{TeO}_{2}$ Glass. Applied Physics Let- 
ters, 80, 1752-1754. https://doi.org/10.1063/1.1458073

[71] Biju, P.R., Thomas, V., Nampoori, P. and Unnikrishnan, N.V. (2004) Energy Transfer in $\mathrm{Sm}^{3+}=\mathrm{Ea}^{3-}$ System in Zinc Sodium Phosphate Glasses. Optical Materials, 24, 671-677. https://doi.org/10.1016/S0925-3467(03)00183-6

[72] Tanabe, S. (2001) Optical Transition of Rare Earth Ions for Amplifiers: How the Local Structure Works in Glass. Journal of Non-Crystalline Solids, 259, 1-9.

[73] Kaundel, R.S., Kaur, S. and Singh, N. (2010) Investigation of Structural Properties of Lend Strontium Borate Glasses for Gamma-Ray Shield Applications. Journal of Physics Chemistry Solids, 71, 1195. https://doi.org/10.1016/j.jpcs.2010.04.016

[74] Fu, Q., Rahaman, N. and Fu, H. (2010) Silicate, Borosilicate, and Borate Bioactive Glass Scaffolds with Controllable Degradation Rate for Bone Tissue Engineering Applications. 1. Preparation and In Vitro Degradation. Journal of Biomedical Materials Research Part A, 95, 164-171. https://doi.org/10.1002/jbm.a.32824

[75] Dimitrov, V. and Komatsu, T. (2012) Correlation among Electronegativity, Cation Polarizability, Optical Basicity and Single Bond Strength of Simple Oxides. Journal of Solid State Chemistry, 196, 574-578. https://doi.org/10.1016/j.jssc.2012.07.030

[76] Reddy, R.R., Ahammed, Y.N. and Azeem, A. (2001) Electronic Polarizability and Optical Basicity Properties of Oxide Glasses through Average Electronegativity. Journal of Non-Crystalline Solids, 286, 169-180. https://doi.org/10.1016/S0022-3093(01)00481-1

[77] Reddy, R.R., Gopal, K.R. and Ahammed, Y.N. (2005) Correlation between Optical Electronegativity, Molar Refraction, Ionicity and Density of Binary Oxides, Silicates and Minerals. Solid State Ionics, 176, 401-407. https://doi.org/10.1016/j.ssi.2004.07.041

[78] Asokamani, R. and Manjula, R. (1989) Atomic Polarizability and Electronegativity for Some Oxide Glasses. Physical Review B, 39, 4217-4221.

https://doi.org/10.1103/PhysRevB.39.4217

[79] Thombre, D.B. (2014) The Estimation of Oxide Polarizability Using the Electronegativity for $\mathrm{Li}_{2} \mathrm{O}: \mathrm{B}_{2} \mathrm{O}_{3}: \mathrm{SiO}_{2}$ Glass System. International Journal of Science Engineering and Technology, 3, 1047-1050.

[80] Sanderson, R.T. (1952) Electronegativities in Inorganic Chemistry. Journal of Chemical Education, 29, 539-544. https://doi.org/10.1021/ed029p539

[81] Onoda, J., Ondracek, M., Jelinek, P. and Sugimoto, Y. (2017) Electronegativity Determination of Individual Surface Atoms by Atomic Force Microscopy. Nature Communication, 8, Article No. 15155. https://doi.org/10.1038/ncomms15155 